ARTICLE

Check for updates

https://doi.org/10.1038/s41467-021-22077-4

\title{
OPEN
}

\section{The box C/D snoRNP assembly factor Bcd1 interacts with the histone chaperone Rtt106 and controls its transcription dependent activity}

\author{
Benoît Bragantini (10 1,6,8, Christophe Charron 1,8, Maxime Bourguet ${ }^{2,8}$, Arnaud Paul11,8, Decebal Tiotiu1, \\ Benjamin Rothé ${ }^{1} 7$, Hélène Marty ${ }^{1}$, Guillaume Terral ${ }^{2}$, Steve Hessmann², Laurence Decourty ${ }^{3}$, \\ Marie-Eve Chagot ${ }^{1}$, Jean-Marc Strub ${ }^{2}$, Séverine Massenet ${ }^{1}$, Edouard Bertrand (10 ${ }^{4}$, Marc Quinternet ${ }^{5}$, \\ Cosmin Saveanu (10 ${ }^{3}$, Sarah Cianférani ${ }^{2}$, Stéphane Labialle (i) ${ }^{1,9 凶}$, Xavier Manival (D) ${ }^{1,9 凶} \&$ \\ Bruno Charpentier (1D) 1,9凶
}

Biogenesis of eukaryotic box $\mathrm{C} / \mathrm{D}$ small nucleolar ribonucleoproteins initiates co-transcriptionally and requires the action of the assembly machinery including the Hsp90/R2TP complex, the Rsalp:Hit1p heterodimer and the Bcd1 protein. We present genetic interactions between the Rsalp-encoding gene and genes involved in chromatin organization including RTT106 that codes for the H3-H4 histone chaperone Rtt106p controlling H3K56ac deposition. We show that Bcd1p binds Rtt106p and controls its transcription-dependent recruitment by reducing its association with RNA polymerase II, modulating H3K56ac levels at gene body. We reveal the 3D structures of the free and Rtt106p-bound forms of Bcd1p using nuclear magnetic resonance and X-ray crystallography. The interaction is also studied by a combination of biophysical and proteomic techniques. Bcdlp interacts with a region that is distinct from the interaction interface between the histone chaperone and histone $\mathrm{H} 3$. Our results are evidence for a protein interaction interface for Rtt106p that controls its transcription-associated activity.

\footnotetext{
${ }^{1}$ Université de Lorraine, CNRS, IMoPA, Nancy, France. ${ }^{2}$ Laboratoire de Spectrométrie de Masse BioOrganique, Université de Strasbourg, CNRS IPHC UMR 7178, Strasbourg, France. ${ }^{3}$ Génétique des Interactions Macromoléculaires, Département de Génomes et Génétique, Institut Pasteur (UMR3525-CNRS), Paris, France. ${ }^{4}$ IGH, CNRS, Université de Montpellier, Montpellier, France. ${ }^{5}$ Université de Lorraine, CNRS, INSERM, IBSLor, Nancy, France. ${ }^{6}$ Present address: Department of Biochemistry and Molecular Biology, Mayo Clinic, Rochester, MN, USA. ${ }^{7}$ Present address: Ecole polytechnique fédérale de Lausanne (EPFL) SV ISREC, Station 19, Lausanne, Switzerland. ${ }^{8}$ These authors contributed equally: Benoit Bragantini, Christophe Charron, Maxime Bourguet, Arnaud Paul. ${ }^{9}$ These authors jointly supervised this work: Stéphane Labialle, Xavier Manival, Bruno Charpentier. ${ }^{凶}$ email: stephane.labialle@univ-lorraine.fr; xavier.manival@univ-lorraine.fr; bruno.charpentier@univ-lorraine.fr
} 
S mall nucleolar RNAs (snoRNAs) form a large abundant family of noncoding RNAs predominantly localized in the nucleolus ${ }^{1}$. Based on conserved sequence motifs, snoRNAs fall into one of two classes-box C/D snoRNAs or box H/ACA snoRNAs. Each snoRNA associates with a set of class-specific and well-characterized core proteins to form ribonucleoprotein (RNP) complexes referred to as small nucleolar ribonucleoproteins, i.e., box C/D snoRNPs and box H/ACA snoRNPs. These particles primarily catalyze post-transcriptional modifications in ribosomal $\mathrm{RNAs}^{2}$ (rRNAs). In these reactions, the snoRNA functions as a guide by base-pairing with a target sequence and selecting the precise nucleotide that will be modified by the catalytic activity of the snoRNP ${ }^{3}$. A few other snoRNPs, e.g., U3, are involved in endo-ribonucleolytic processing of the original prerRNA transcript ${ }^{4,5}$.

Eukaryotic snoRNP biogenesis is a complex process that involves coordinated assembly, RNA processing, and localization factors $^{6}$. In yeast, box C/D snoRNPs are formed by assembling core proteins Snu13, Nop56, Nop58, and 2'-O-methyl transferase Nop1 on box C/D snoRNAs. This process requires assembly machinery including the protein heterodimer Rsa1:Hit ${ }^{7}$ and the R2TP chaperone complex, which is composed of proteins Pih1, Tah1, and AAA + ATPases Rvb1 and Rvb2 (Rvb1/2) ${ }^{8,9}$. In addition, the Bcd1 protein is essential for both cell viability and box C/ D snoRNA steady-state stability ${ }^{10,11}$, and was shown to control the loading of Nop58p to pre-snoRNPs ${ }^{12}$. A conserved motif in the $\mathrm{N}$-terminal region of $\mathrm{Bcd} 1 \mathrm{p}$ was proposed as a determinant for binding with Snu13p and snoRNA ${ }^{13}$. This tripartite R2TP/ Rsalp:Hitlp/Bcd1p machinery is conserved in metazoans and plants where it is also used for snoRNP biogenesis $8,14-18$. The human ortholog of R2TP associates with an additional prefoldinlike (PFDL) module to form a larger chaperone complex called the PAQosome ${ }^{19}$. This chaperone is involved in the folding of critical macrocomplexes, e.g., RNPs involved in fundamental cellular processes, and RNA polymerases.

Here we show that the snoRNP assembly factor gene RSA1 genetically interacts with genes involved in chromatin structure and nucleosome assembly including histone chaperones such as Rtt106p (Regulator of Ty transposition), as well as with genes involved in transcription añd RNA processing. We also demonstrate that the box C/D snoRNP assembly factor Bcdlp binds Rtt106p directly. This chaperone cooperates with the H3-H4 histone chaperone CAF-1 (chromatin assembly factor 1) and with the heterodimeric chaperone FACT (facilitates chromatin transcriptions, composed of the Spt16p:Pob3p heterodimer) to facilitate DNA replication-coupled (RC) nucleosome assembly ${ }^{20,21}$. During this process, Rtt106p participates in the deposition of newly synthesized H3K56ac-carrying H3:H4 complex on replicating DNA ${ }^{22-26}$. In addition, Rtt106p is involved in replicationindependent pathways including heterochromatin silencing ${ }^{20,27}$, HIR-dependent control of histone gene expression ${ }^{28}$, regulation of transcription-dependent histone $\mathrm{H} 3$ deposition during RNA polymerase elongation $^{29}$, and maintenance of promoter fidelity in cooperation with HIR (histone regulatory) and Asf1 (anti-silencing factor 1) proteins ${ }^{30}$.

Our data reveal a Bcd1p-dependent association of Rtt106p on box C/D pre-snoRNAs, with no discernible effect on snoRNP assembly. On the contrary, we observe that the association of Rtt106p with transcriptionally active loci correlates with its association with RNA polymerase II, and that these associations are negatively modulated by Bcdlp. In coherence with these observations, we show that $\mathrm{H} 3 \mathrm{~K} 56 \mathrm{ac}$ levels are increased at several gene bodies upon Bcdlp depletion. We characterize this important Bcd1p:Rtt106p interaction for the transcriptiondependent Rtt106p function at the molecular and atomic levels. A combination of ITC, MS approaches, NMR, and X-ray show that Bcd1p binds with the PH1 (Pleckstrin-Homology 1) domain of Rtt106p. These data support a model in which the binding of Bcd1p to Rtt106p can inhibit the transcription-related activities of this histone chaperone.

\section{Results}

Genetic Interaction Mapping (GIM) screens of the C/D snoRNP assembly factor gene RSA1. To identify potential genetic interactions with the snoRNP assembly machinery, we performed a high-throughput genetic screen. We used deletion of RSA1 ( $\left.r s a 1 \Delta:: p r M F \alpha 2 N a t^{R}\right)$ as the query mutation and combined it in a single pool by mating it with individual mutants of the yeast systematic deletion library of nonessential genes ${ }^{31}$ and with a collection of DAmP (decreased abundance by mRNA perturbation) mutants for essential genes ${ }^{32,33}$. Double mutants were selected from the pool after sporulation and grown for $\sim 18$ generations in rich liquid medium. In parallel, a similar screen was performed with other mutant strains for use as a control population. The relative growth rates of double mutant strains were estimated by measuring the relative abundance of cells in the query versus reference populations using DNA barcodes and microarrays. Normalized results are expressed as $\log 2(\mathrm{Q} / \mathrm{R})$ where $\mathrm{Q}$ represents the signal intensities of the tag marking a given mutant when combined with the query mutation, and $\mathrm{R}$ is the signal from the same mutant when introduced in the reference population. In agreement with previous GIM screens, we obtained a relatively large number of both negative and positive $\log 2(\mathrm{Q} / \mathrm{R})$ values, representing aggravating and buffering (or alleviating) effects, respectively (Source data file). In agreement with the contribution of Rsalp to snoRNP biogenesis and validating the approach, we observed strong genetic links between $R S A 1$ and $R V B 1$, encoding one of the R2TP components, and NOP56, encoding one of the box C/D core proteins (Fig. 1). However, whereas a negative value $(\log 2(\mathrm{Q} / \mathrm{R})=-1.8)$ was obtained for the rvb1-DAMP mutation pointing to a synthetic growth defect, combining rsal $\triangle$ mutation with the nop56-DAMP mutation had an epistatic effect with a positive value $(\log 2(\mathrm{Q} / \mathrm{R})$ $=+3.0)$.

We used g:Profiler [https://biit.cs.ut.ee/gprofiler/gost] to check if specific annotations were enriched among our results. The list of the top 50 mutants showing an epistatic or suppressor effect in combination with $r s a 1 \Delta$ was enriched in two broad gene ontology (GO) categories: mRNA metabolic process (GO:0016071) and chromatin organization (GO:0006325). For a more detailed view of which specific processes among RNA metabolism and chromatin organization were affected by RSA1 deletion, we used a curated list of 518 yeast complexes ${ }^{34}$ and searched for gene set enrichment in the GIM screen data using GAGE ${ }^{35}$. Among the top results, we found genes, e.g., SPT21, encoding proteins implicated in transcriptional silencing and required for normal transcription at other loci including HTA2-HTB2 and HHF2HHT2 that encode histone proteins. Deletion of genes involved in termination and processing of the 3' end of pre-snoRNAs rescued growth of $r s a 1 \Delta$ cells, including the exosome components MTR3, RRP42, RRP46, and CSL4, as well as the LEO1 and RTF1 subunits of the PAF complex, which is involved in transcription elongation (Fig. 1). It is conceivable that impairing these RNA processing events compensates for the imperfect box C/D snoRNP assembly resulting from the rsa1 $\Delta$ disruption. Assembly of snoRNP starts early on nascent snoRNAs and this process has been proposed to be coupled to $3^{\prime}$ processing ${ }^{36,37}$. One possibility is that RNP assembly is delayed in the rsa $1 \Delta$ mutant and becomes kinetically uncoupled from 3' processing. Slower transcription termination and $3^{\prime}$ processing would then compensate the slower RNP assembly. 


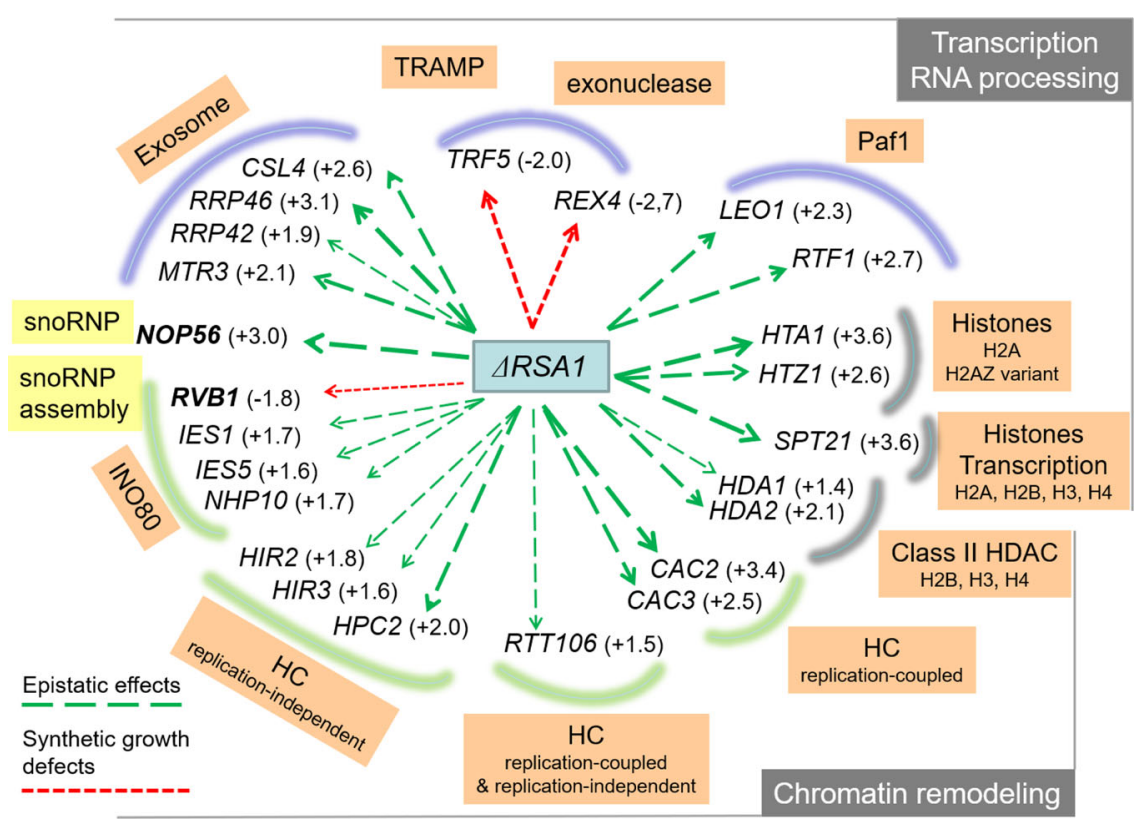

Fig. 1 Data from the GIM screen. Two independent screens were performed, one with a mutant strain in which the RSA1 gene was deleted (rsa1 $\Delta:: N a t R$ ) and the other with a mutant used as reference strain. Two independent experiments were performed for each of these screens. The query strain and the reference strain were mated with a pool of strains containing all the viable strains from the haploid gene deletion collection. After selection of heterozygous diploids, sporulation and selection of the haploid, double mutants were grown for $\sim 18$ generations in rich liquid medium (YPD). Microarrays were used to measure the relative abundance of double mutants with query versus the reference populations. Normalized results are expressed as log2(Q/R) (see Methods section). Negative values indicate a synthetic growth defect. Positive values reveal either epistatic (buffering) or suppressive (alleviating) interactions between RSA1 and the selected genes. The genetic interactions with RSA1 are indicated by green arrows for the positive log2(Q/R) values and by red arrows for the negative values. The exact values are given in parentheses. $\mathrm{HC}$ heterochromatin.

In addition, deletion of RSA1 had multiple epistatic effects when combined with deletion of genes encoding components of the chromatin remodeling complexes HIR (HIR2, HIR3, HPC2), INO80 (IES1, IES5, NHP10), and CAF-1 (CAC2 and CAC3), as well as genes HDA1 and HDA2 encoding members of the HDA1 histone deacetylase complex and genes encoding histone variants (HTZ1 and HTA1; Fig. 1). Interestingly, rsa1 $\Delta$ had a positive $\log 2$ $(\mathrm{Q} / \mathrm{R})$ value $(+1.5)$ in combination with the deletion of RTT106, which is connected to the HIR and CAF- 1 complexes ${ }^{27,28}$. We focused on the Rtt106 protein as it is linked to several fundamental functions such as DNA replication, stability, and transcription, but not yet to snoRNP biogenesis and function, except for the observation based on modified chromatin immunopurification $^{38}$ (mChIP) suggesting that it can associate with complexes containing Rvb1/2 proteins in the vicinity of chromatin.

Rtt106p binds Bcdlp. To investigate interactions between Rtt106p and the proteins known to be involved in snoRNP biogenesis, we performed systematic pairwise yeast two-hybrid $(\mathrm{Y} 2 \mathrm{H})$ assays. This revealed a strong in vivo interaction between Rtt106p and Bcd1p, which resisted high concentrations of 3-AT (30-40 mM; Fig. 2a). The Y2H interaction derived from the middle domain of Rtt106p encompassing the tandem $\mathrm{PH} 1$ and $\mathrm{PH} 2$ domains. Indeed, full-length Bcdlp (Bcdl $\left.\mathrm{p}_{\mathrm{FL}}\right)$ interacted with the fragment of Rtt106p spanning amino acids 65-320 (Rtt106 $\mathrm{p}_{65-320}$ also named Rtt106p-M, Fig. 2a). This interaction was specific as it was not detected with the homologous $\mathrm{PH}$ domains from histone chaperones Pob3p and Spt16p (Fig. 2a) that are members of the FACT chromatin remodeling complex $22,39,40$.

To validate the Bcdlp:Rtt106p interaction, we used pull-down assays in yeast cells engineered to express the tagged proteins 3xHA-Bcd1p and Rtt106-TAP from their genome (Fig. 2b).
Retention of 3xHA-Bcdlp on beads occurred with the copurification of Rtt106p-TAP. To determine whether this interaction is direct, we performed co-purification assays in Escherichia coli upon ectopic co-expression of different combinations of truncated or full-length $\mathrm{His}_{6}$-tagged and untagged proteins (Fig. 2c). The co-expressed proteins in the bacterial extract were co-purified by immobilized metal ion affinity chromatography (IMAC), fractionated by SDS-PAGE and analyzed by mass spectrometry (MS) (Supplementary Table 1). This confirmed the

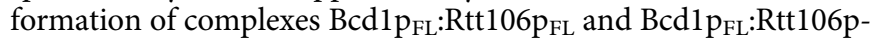
M. Recombinant Bcdlp $\mathrm{p}_{\mathrm{FL}}$ and the fragment Rtt106p-M were also independently purified and isothermal titration calorimetry (ITC) revealed direct and endothermic in vitro binding with a $1.17 \pm 0.17 \mu \mathrm{M}$ dissociation constant $\left(K_{\mathrm{d}}\right.$; Fig. $2 \mathrm{~d}$, left panel).

We completed these data by native MS analysis of the coexpressed complex Bcd1 $\mathrm{p}_{\mathrm{FL}}: \mathrm{Rtt} 106 \mathrm{p}-\mathrm{M}$ and its individual subunits (Fig. 2e). Bcdlp $\mathrm{p}_{\mathrm{FL}}$ was mainly detected as a monomer in interaction with two zinc ions $(42,752 \pm 1 \mathrm{Da}$, Fig. 2e upper spectrum), as already reported ${ }^{41}$. For Rtt106p-M, monomeric species were also mainly detected $(29,695 \pm 1 \mathrm{Da}$, Fig. 2e middle spectrum). Finally, native MS revealed the formation of a 1:1 Bcdlp $\mathrm{F}_{\mathrm{FL}}:$ Rtt106p-M heterodimer with a mass of $72,451 \pm 1 \mathrm{Da}$. These data demonstrated that $\mathrm{Bcdlp}_{\mathrm{FL}}$ binds the 65-320 (M) domain of Rtt106p with 1:1 stoichiometry.

We then monitored the Bcdl $\mathrm{p}_{\mathrm{FL}}:$ Rtt106p-M heterodimer formation by ion mobility coupled with mass spectrometry (IM-MS). This approach makes it possible to determine collision cross section $\left({ }^{\mathrm{TW}} \mathrm{CCS}_{\mathrm{N} 2}\right)$ by measuring the drift time of ions through a gas-filled IM cell. The arrival drift time (ADT) is closely linked to the charge state and to the shape of the ions in the gas phase ${ }^{42}$. IM-MS data and ${ }^{\mathrm{TW}} \mathrm{CCS}_{\mathrm{N} 2}$ measured for each individual subunit Bcdl $\mathrm{p}_{\mathrm{FL}}$ and Rtt106p-M and for the Bcdl $\mathrm{p}_{\mathrm{FL}}$ : Rtt106p-M heterodimer (Supplementary Fig. 1) revealed that a significant conformational change occurs in one or both proteins 
a

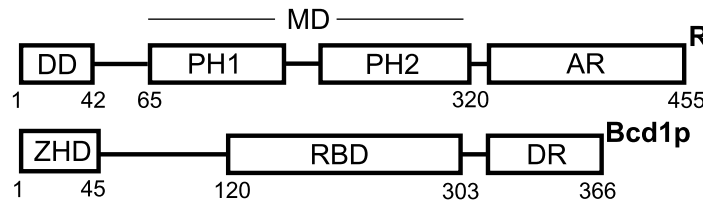

Rtt106p

\section{p}

b

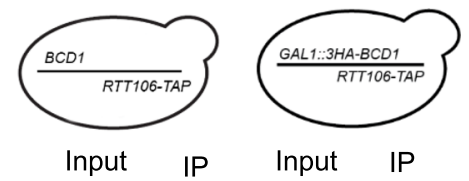

Gal4-BD Gal4-AD

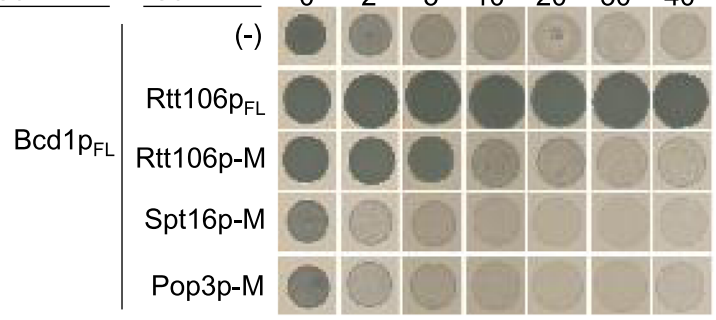

$(10 \%)$ HA $(10 \%)$ HA

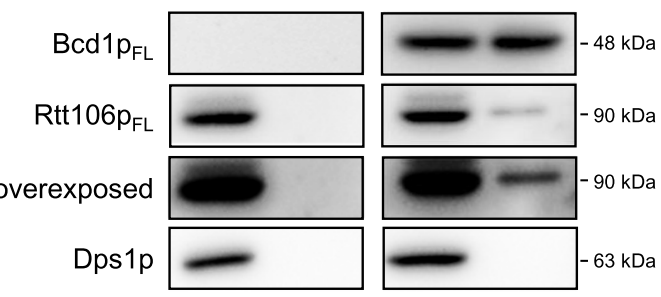

C

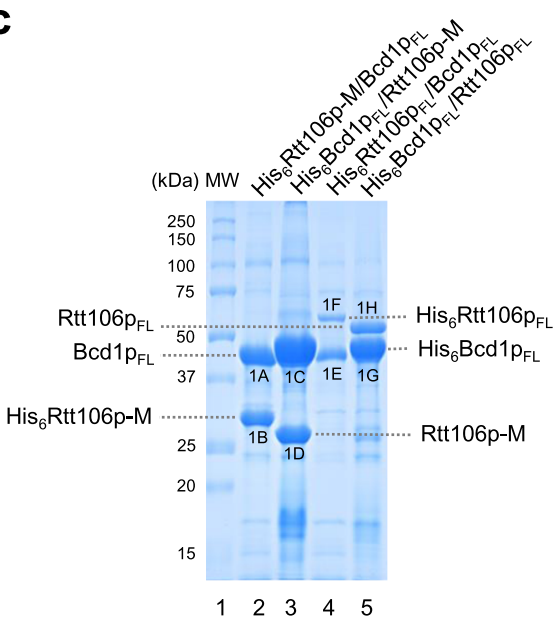

d $\quad B c d 1 p_{\mathrm{FL}}$

+ Rtt106p-M

Bcd1 $p_{120-303}$

Time (min)

+ Rtt106p $p_{65-301}$

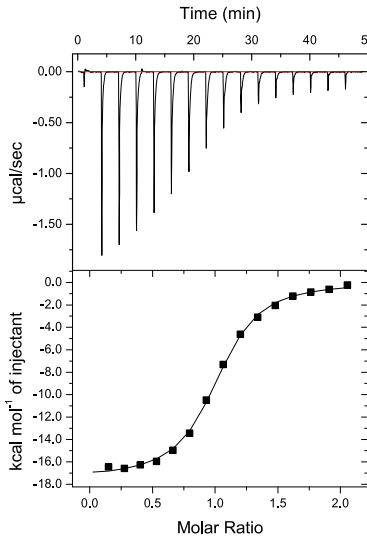

$K_{d}=1.17 \pm 0.17 \mu \mathrm{M}$

$\Delta H=-1.743 \times 10^{4} \pm 146.1 \mathrm{cal} / \mathrm{mo}$

$\Delta S=-32.3 \mathrm{cal} / \mathrm{mol} / \mathrm{deg}$

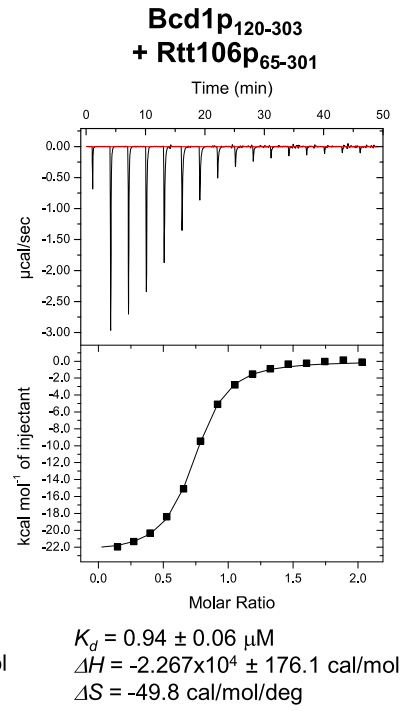

e

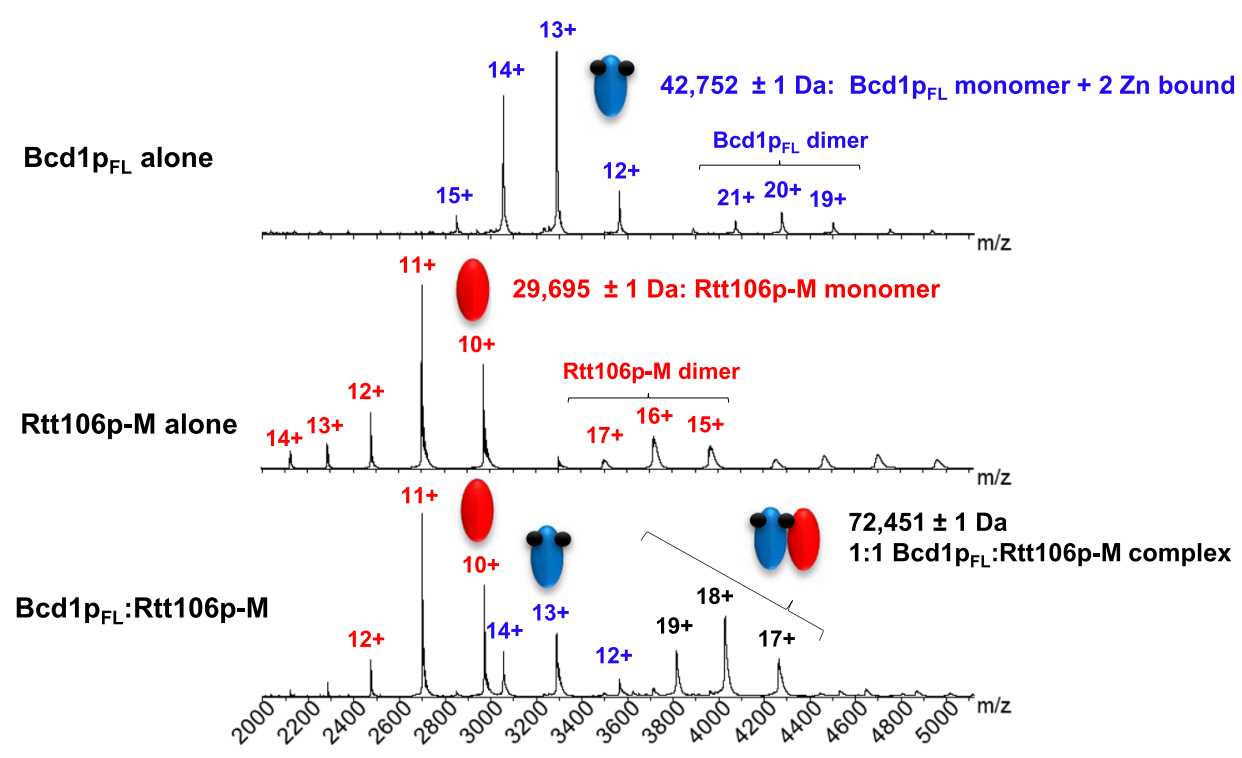

upon heterodimer formation. The IM-MS measured ${ }^{{ }^{T}}{ } \mathrm{CCS}_{\mathrm{N} 2}$ $\left(44.4 \pm 1.4 \mathrm{~nm}^{2}\right)$ was larger than the value expected from mass and $15 \%$ smaller than the one predicted from a juxtaposition of the two subunits. We concluded that the heterodimer is not formed merely by simple juxtaposition of the two partners.
Rtt106p binds pre-snoRNPs but does not appear to contribute to or interfere with snoRNP biogenesis. To investigate if Rtt106p contributes to snoRNP biogenesis, we used RNA immunoprecipitation (RIP) assays. We observed that Rtt106pTAP was highly enriched on box C/D snoRNAs U3, U14 and the 
Fig. 2 Bcd1p and histone chaperone Rtt106p form a stable heterodimer. a Schematic representation of the Rtt106p and Bcd1p domain organization. DD dimeric domain, $\mathrm{PH}$ Plekstrin homology, $\mathrm{PH} 1+\mathrm{PH} 2=\mathrm{MD}$ middle domain, AR acidic region, ZHD zinc finger HIT domain, RBD Rtt106 binding domain, DR disorder region. $\mathrm{Y} 2 \mathrm{H}$ assay: full-length $\mathrm{Bcd1p}\left(\mathrm{Bcd} 1 \mathrm{p}_{\mathrm{FL}}\right)$ fused to the $\mathrm{Gal} 4$ binding domain $(\mathrm{BD})$ interacts with the full-length $\mathrm{Rtt106p}\left(\mathrm{Rtt} 106 \mathrm{p}_{\mathrm{FL}}\right)$ or fragment spanning amino acids 65-320 (Rtt106p-M) fused to the Gal4 activation domain (AD) as evidenced by growth on a His deprived medium supplemented with increased concentrations of 3-amino-1, 2, 4-triazol (3-AT). No interaction was observed with homologous fragments of FACT chaperone components Spt16p and Pob3p (Spt16p-M and Pob3p-M). b Interaction of Bcd1 $\mathrm{p}_{\mathrm{FL}}$ with Rtt106 $\mathrm{p}_{\mathrm{FL}}$ in yeast. Co-immunoprecipitation (co-IP) was performed on GAL1::3HA-BCD1 $\times$ RTT106-TAP cells expressing 3xHA-tagged Bcd1 $\mathrm{F}_{\mathrm{FL}}$ and TAP-tagged Rtt106 $\mathrm{p}_{\mathrm{FL}}$. Cells expressing the nontagged Bcd1p were used as negative control. Extracts were incubated with anti-HA beads. The co-immunoselected proteins were analyzed by SDS-PAGE and western blotting. $10 \%$ of total proteins used per assay were loaded in the input lane. Tagged proteins were detected with PAP antibodies for Rtt106p and anti-HA antibodies for Bcd1p. The Dps1 protein used to control protein loading was detected using specific anti-Dps1p antibodies. The two panels correspond to a cropping of two sections of the same membrane. The full-length membrane is presented in the Source data file. The experiment was independently repeated three times with similar results. c Interaction of recombinant Bcd1p and Rtt106p in E. coli. His 6 -tagged full-length or M domain of Rtt106p were co-expressed with $\mathrm{Bcd1} \mathrm{p}_{\mathrm{FL}}$. His ${ }_{6}$-tagged Bcd1 $\mathrm{p}_{\mathrm{FL}}$ was co-expressed with Rtt106 $\mathrm{p}_{\mathrm{FL}}$ or Rtt106p-M. Complexes were selected from crude extract by immobilized metal ion affinity chromatography (IMAC), fractionated by SDS-PAGE and revealed by Coomassie blue staining. The results correspond to co-expression with high salt $(400 \mathrm{mM})$ buffer. Molecular weight markers $(\mathrm{MW})$ in kilo Dalton $(\mathrm{kDa})$ were loaded on the left. The experiment was repeated twice with similar results. The identity of the proteins in bands $1 \mathrm{~A}, 1 \mathrm{~B}, 1 \mathrm{C}, 1 \mathrm{D}, 1 \mathrm{E}, 1 \mathrm{~F}, 1 \mathrm{G}$, and $1 \mathrm{H}$ was confirmed by in-gel digestion of gel slices and mass spectrometry (MS) analysis of the peptide extract (Supplementary Table 1). $\mathbf{d}$ Bcd1p and Rtt106p interacting domains. ITC data for the interaction of Bcd1 $\mathrm{p}_{\mathrm{FL}}$ with Rtt106p-M (on the left) and Bcd1p $120-303$ with Rtt106 $\mathrm{p}_{65-301}$ (on the right) recorded at $293 \mathrm{~K}$ in buffer containing $10 \mathrm{mM} \mathrm{NaPi}$ at pH 7.5, $150 \mathrm{mM} \mathrm{NaCl}$ and $0.5 \mathrm{mM}$ TCEP. The calculated affinities $K \mathrm{~d}$, and thermodynamic parameters as variations in enthalpy $(\Delta H)$ and entropy $(\Delta S)$ are indicated. e Nondenaturing MS characterization of the complex formed upon incubation of recombinant Bcd1p $\mathrm{FL}_{\mathrm{F}}$ with fragment Rtt106p-M. NanoESI mass spectra performed under nondenaturing conditions confirmed the presence of a 1:1 binding stoichiometry of Bcd1 $\mathrm{p}_{\mathrm{FL}}: \mathrm{Rtt} 106 \mathrm{p}-\mathrm{M}$ complex (Da $=\mathrm{Dalton}$ ). Source data for panel b are provided as a Source Data file.

precursor form of U14 (Fig. 3a). Moreover, using GAL1::3HA$B C D 1$ cells grown in galactose-containing (YPG) medium for expression of Bcdlp and in glucose-containing (YPD) medium for depletion of $B c d 1 p^{12}$, we showed that the association of Rtt106p with these snoRNAs is Bcdlp dependent. Using the rsa1s mutant cells, we showed that binding of Rtt106p with RNPs containing Bcd1p is also Rsalp-dependent, which could be explained by the fact that a detectable association of Bcd1p with snoRNA species is Rsalp-dependent (Supplementary Fig. 2a). Although these data revealed the presence of Rtt106p on box C/D pre-snoRNPs, the hypothesis of a role for Rtt106p in facilitating or modulating the function of Bcdlp in snoRNP biogenesis seemed unlikely. Indeed, the steady-state levels of box C/D presnoRNAs and their mature forms did not change in absence of Rtt106p expression, at least in yeast cells grown in standard culture conditions (Supplementary Fig. 2b). Accordingly, enrichments of Bcdlp to box C/D snoRNAs (Supplementary Fig. 2c) and to snoRNA gene loci did not change appreciably in the absence of Rtt106p (Supplementary Fig. 2d).

Bcd1p regulates the presence of $\mathrm{Rtt106p}$ at transcriptionally active loci. To investigate a potential regulatory function of Bcd1p in Rtt106p activity, we checked whether the recruitment of Rtt106p to DNA loci could be Bcdlp dependent. Using ChIP, we analyzed the presence of FLAG-tagged Rtt106p to the HIRdependent histone genes HTA1-HTB1 and to the HMR locus where Rtt106p has been shown to be enriched $26,30,43,44$. Enrichment in GAL1::3HA-BCD1 cells at box C/D snoRNA-encoding genes SNR17A (U3), SNR128 (U14), SNR52 (snR52), and SNR32 encoding box H/ACA snoRNA snR32, as well as at the protein encoding gene $A L G 9$ was tested for the purpose of comparison (Fig. 3b). Enrichment of Rtt106p at either C/D box or H/ACA box snoRNA gene loci was equivalent to enrichment at HTA1HTB1 locus. Therefore, as described for coding genes that are actively transcribed ${ }^{29,45}$, Rtt106p likely acts as a histone chaperone at snoRNA gene loci. Disruption of the RSA1 gene has no effect on the presence of Rtt106p to these loci. However, we observed that this enrichment increased significantly in the absence of $B C D 1$ gene expression, i.e., in YPD medium, at actively transcribed loci, but not at a chromosome $\mathrm{V}$ region devoid of transcription (Fig. 3b). To confirm that Bcdlp affects the transcription-related recruitment of Rtt106p, we solved the pattern of association at the U3 actively transcribed loci (Fig. 3c). Rtt106p enrichment increased in the body of the gene compared to the flanking intergenic regions, and the association was sensitive to the level of expression of Bcdlp only in the transcribed region. To test the possibility that association to chromatin relied on RNA, we performed ChIP analyses in the presence of RNase treatment (Supplementary Fig. 2e). Interestingly, we observed a slight reduction of ChIP signals at both transcribed and untranscribed loci, suggesting that Rtt106p associated moderately via undetermined chromatin-associated RNA species. Importantly, the effect of RNase treatment was similar in cells expressing or not Bcdlp, excluding the possibility that it occurs in a Bcd1pdependent way. Therefore, the data suggest that Rtt106p interacts with chromatin by several, independent ways with at least one involving RNAs present at the vicinity of chromatin (including at untranscribed loci), and a second one that is independent from RNA but dependent on Bcd1p expression level.

Bcd1p controls the association of Rtt106p with RNA polymerase II and H3K56ac levels at gene bodies. As it has been proposed that Rtt106p acts in the wake of the transcriptional machinery to promote new histone deposition ${ }^{29}$, we first tested whether an interaction between Rtt106p and RNA polymerase II was detectable. Using co-IP, we indeed observed that Rtt106p was associated with Rpb1p, the largest RNA polymerase II subunit (Fig. 4a). Interestingly and in agreement with an effect of Bcdlp on transcription-related Rtt106 $\mathrm{p}$ function, this association increased in the absence of $B C D 1$ gene expression. Taken together, these data suggest that direct binding of Bcd1p with Rtt106p precludes association of the histone chaperone with the RNA polymerase II, and therefore reduces its presence at transcriptionally active loci. In agreement with this proposal, the presence of histone $\mathrm{H} 3$ acetylated at lysine 56 (H3K56ac) was found to be higher in these transcribed regions upon $\operatorname{Bcdlp}$ depletion (Fig. 4b). We concluded that Bcdlp negatively regulates the histone chaperone activity of Rtt106p during transcription.

Identification of the Rtt106p binding domain in Bcd1p. Sequence analysis of Bcdlp did not enable us to predict the 
a
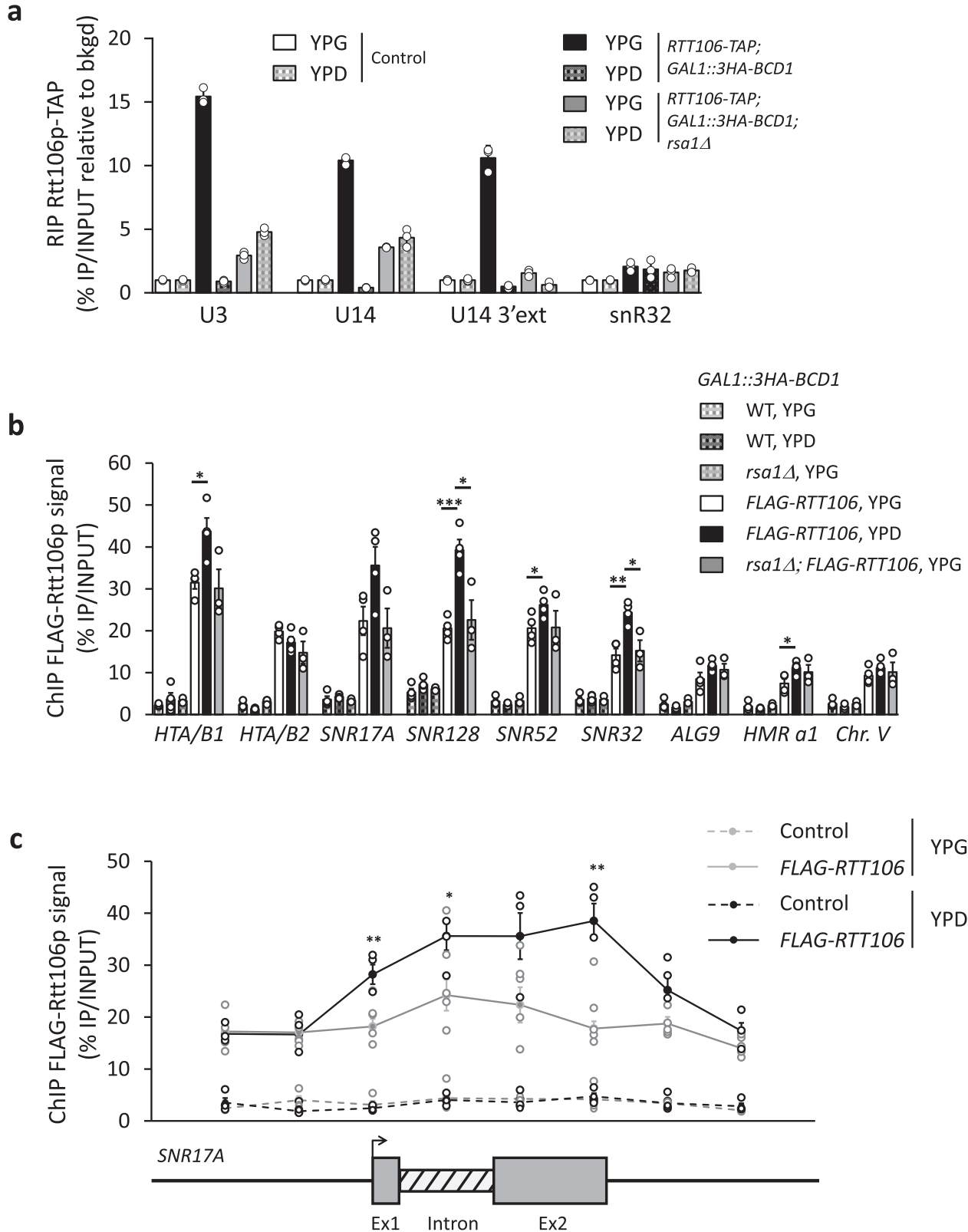

Fig. 3 Interaction of Rtt106p with selected transcripts and loci. a RNA immunoprecipitation (RIP) assays were performed on extracts prepared from RTT106-TAP; GAL1:3HA-BCD1 cells disrupted (rsa1A) or not of the RSA1 ORF. The cells were cultivated in the presence of galactose (YPG) or shifted to a glucose-containing medium (YPD) for $6 \mathrm{~h}$ before preparation of the extract. IP was performed using lgG-sepharose beads. RNAs retained on beads were quantified by RT-qPCR as described in the Methods section. The snoRNAs and pre-snoRNAs analyzed are indicated. $\mathbf{b}$ Chromatin immunoprecipitation (ChIP) assays were performed on yeast GAL1:3HA-BCD1 cells transformed with recombinant plasmid FLAG-RTT106; with ( $r$ sa1A) or without the disruption of the RSA1 ORF. Cells were cultivated in YPG or shifted to YPD medium before ChIP assays. Cells expressing nontagged Rtt106p (GAL1:3HA-BCD1 and GAL1:3HA-BCD1; rsa1 $)$ were used as controls and IP was performed using anti-FLAG antibody. The loci analyzed by qPCR analysis are indicated. c Chip assays performed as in panel $\mathbf{b}$ on GAL1:3HA-BCD1 cells transformed with recombinant plasmid FLAG-RTT106. Primers were used for qPCR analysis on both side and across the U3 encoding gene (SNR17A). Data reported in the panels a and $\mathrm{c}$ are mean values plus standard error of the mean of three biological replicates $(n=3)$. Data reported in panel $\mathbf{b}$ are mean values plus standard error of the mean of three (for GAL1::3HA-BCD1, rsa1 $+\mathrm{p} 413(-)$ and GAL1::3HA-BCD1, rsa1D + p413::FLAG-RTT106; $n=3$ ) or four (for GAL1::3HA-BCD1 + p413 (-) and GAL1::3HA-BCD1 + p413::FLAG-RTT106; $n=4$ ) biological replicates. Two-tailed $t$-tests: ${ }^{\star} P<0.05,{ }^{\star \star} P<0.01,{ }^{\star \star \star} P<0.001$. In panel $\mathbf{b}$, for FLAG-RTT106 YPG versus YPD: ${ }^{\star}=0.012$ for $H T A / B 1,{ }^{\star \star \star}=0.0006$ for SNR128 (U14), ${ }^{\star}=0.045$ for SNR52, ${ }^{\star \star}=0.002$ for $S N R 32,{ }^{*}=0.032$ for HMR a1. Note that SNR17A (U3) is close to significance: $P=0,056$. For FLAG-RTT106 YPG versus rsa14; FLAG-RTT106 YPG: ${ }^{\star}=0.02$ for SNR128 (U14) and ${ }^{\star}=0.017$ for SNR32. In panel c, for FLAG-RTT106 YPG versus YPD: ${ }^{\star \star}=0.006,{ }^{*}=0.031$, and ${ }^{* \star}=0.001$ from the left to the right. Source data for all these panels are provided as Source Data files.

existence of known domain(s) except the zf-HIT domain (ZHD) in the $\mathrm{N}$-terminal part of the protein ${ }^{41}$ (Fig. 2a). To delineate the structural domain that engages Rtt106p, we performed partial proteolysis followed by native MS analysis of the co-purified Bcd1p:His ${ }_{6}$ Rtt106p-M complex. We were able to identify several fragments of Bcdlp that maintain binding with $\mathrm{His}_{6} \mathrm{Rtt} 106 \mathrm{p}-\mathrm{M}$, with most fragments spanning amino acids 113-366 (Supplementary Fig. 3). Guided by these data, we tested the potential interaction of Rtt106p-M with various fragments of Bcdlp by ITC (Fig. 2d right panel and Supplementary Fig. 4). In these studies, 
a
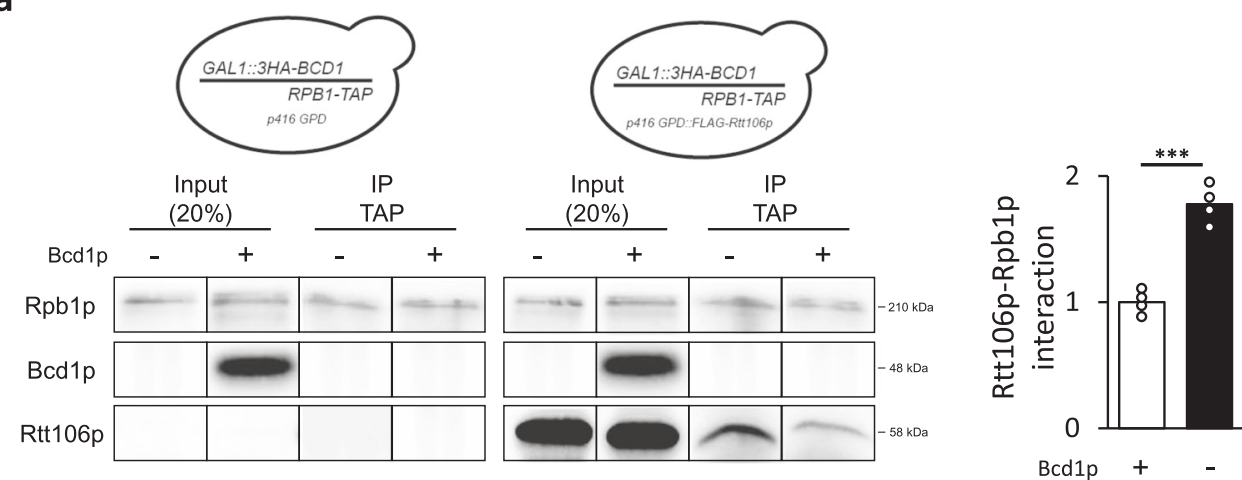

b

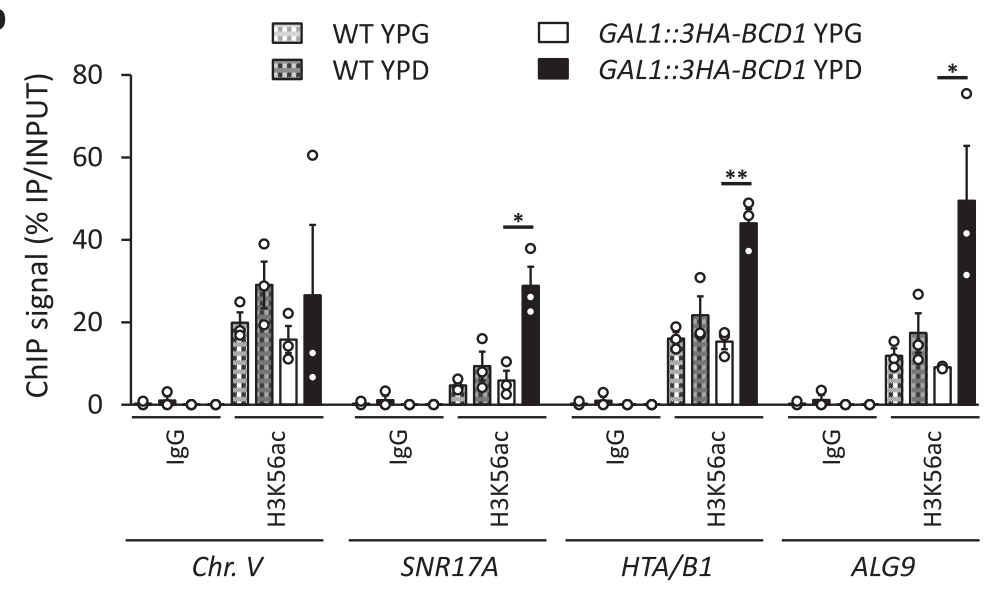

Fig. 4 Bcd1p controls transcription-dependent activity of Rtt106p. a Interaction of Bcd1p with the RNA polymerase II large subunit Rpb1p in yeast. Coimmunoprecipitation (co-IP) was performed on GAL1::3HA-BCD1 × RPB1-TAP cells transformed with p416GDP::FLAG-Rtt106p expressing 3xHA-tagged Bcd1p, TAP-tagged Rpb1p and FLAG-Rtt106p. Cells were transformed with empty vector p416GDP as a control. Cells were grown in YPG (+Bcd1p) or YPD (-Bcd1p). Procedure was as described in Fig. $2 b$ but with the IP performed with anti-TAP antibodies. The image corresponds to a cropping of different sections of the same membrane. The full-length membrane incubated with different antibodies is presented in the Source data file. Histogram on the right presents quantification of Western blots obtained from six independent co-IP experiments. Quantification was performed using Fusion Solo (Vilber Lourmat) and Fusion-Capt Advance Solo 4 software. The FLAG signal (Rtt106p) was normalized to the TAP signal (Rpb1p). The data represent mean values plus standard error to the mean of four biological replicates. b Depletion of Bcd1p affects H3K56ac levels at several RNA polymerase II-dependent genes. ChIP H3K56ac enrichment (IP/INPUT) for parental BY4741 strain and the GAL1::3HA-BCD1 strain grown in YPG (+Bcd1p) or YPD ( - Bcd1p) is presented. Signal specificity was controlled with lgG antibodies. The histogram represents mean values plus standard error to the mean of three biological replicates. Two-tailed $t$-tests: ${ }^{\star} P<0.05,{ }^{\star \star} P<0.01,{ }^{\star \star \star} P<0.001$. In panel $\mathbf{a},{ }^{\star \star \star}{ }^{\star \star}=0.0001$; in panel $\mathbf{b},{ }^{\star}=0.011$ for SNR17A (U3), ${ }^{\star \star}=0.002$ for $H T A / B 1$, ${ }^{\star}=0.039$ for ALG9. Source data for these panels are provided as Source Data files.

the shortest fragment of Bcdlp that conserved the interaction with Rtt106p without decreasing the affinity encompassed amino acids 120-303 (Fig. 2a). We measured a $K_{\mathrm{d}}$ of $0.94 \pm 0.06 \mu \mathrm{M}$ for Bcd1 $p_{120-303}$ vs Rtt106 $\mathrm{p}_{65-301}$, equivalent to the $K_{\mathrm{d}}$ measured with the full-length Bcdlp for Rtt106 $\mathrm{p}_{65-320}$ (Fig. $2 \mathrm{~d}$ left panel). We therefore concluded that the central region of $\mathrm{Bcdlp}$ is necessary and sufficient for interaction with the tandem $\mathrm{PH}$ domains of Rtt106p. Then, we confirmed the direct effect of Bcdlp on Rtt106p-chromatin association by generating the strain $B C D 1_{1-115}$ harboring an endogenous $B C D 1$ gene deleted from the coding region necessary for Bcdlp:Rtt106p binding (Supplementary Fig. $2 \mathrm{f}$ ). Compared to WT cells, Rtt106p was better associated with chromatin in $B C D 1_{1-115}$ cells even if the effect was milder compared to the effect obtained by inducing transient Bcdlp depletion (Fig. 3b, c).

NMR solution structure of $\mathbf{B c d l p}_{\mathbf{1 2 0 - 3 0 3}}$. Sequence comparison between the yeast $\mathrm{Bcd} 1$ protein and its human homologous ZNHIT6 showed that the central Bcd1 $\mathrm{p}_{120-303}$ domain resembles the C-terminal region of ZNHIT6 (Supplementary Fig. 6).
This observation prompted us to search for additional structural information on this domain in an unbound state. We solved the three-dimensional (3D) structure of Bcdlp $\mathrm{p}_{120-303}$ using multidimensional NMR spectroscopy. This stable Bcdlp subfragment provided well-resolved NMR spectra (Fig. 5a), which enabled the unambiguous assignment of more than $90 \%$ of the ${ }^{1} \mathrm{H},{ }^{13} \mathrm{C}$, and ${ }^{15} \mathrm{~N}$ resonances. NMR data provided a well-defined ensemble of 20 water-refined structures with respective backbone and heavy atom RMSD values of $0.74 \pm 0.16 \AA$ and $1.36 \pm 0.20 \AA$ for residues 123-301 (Fig. 5b; statistics are detailed in Table 1). The 120-303 domain is composed of nine $\beta$-strands and six $\alpha$-helices, with strands $\beta 4-7$ and $\beta 9$ forming a central twisted $\beta$-sheet (Fig. $5 c$ and Supplementary Fig. 7). The majority of the helices ( $\alpha 2, \alpha 3$, $\alpha 4$, and $a 5$ ) are packed on one side of the central sheet, while on the opposite side, only the small helix $\alpha 6$, the $\beta 4-\beta 5$ (172-178) and $\beta 6-\beta 7(249-256)$ loops, and the C-terminal region are present. The N-terminal region Bcdlp $\mathrm{p}_{120-149}$, whose deletion prevents binding with Rtt106p (Supplementary Fig. 4 and Supplementary Fig. 5), comprises helix $\alpha 1$ and strands $\beta 1$ and $\beta 2$. Since deletion of this 120-149 region in Bcdlp results in soluble 

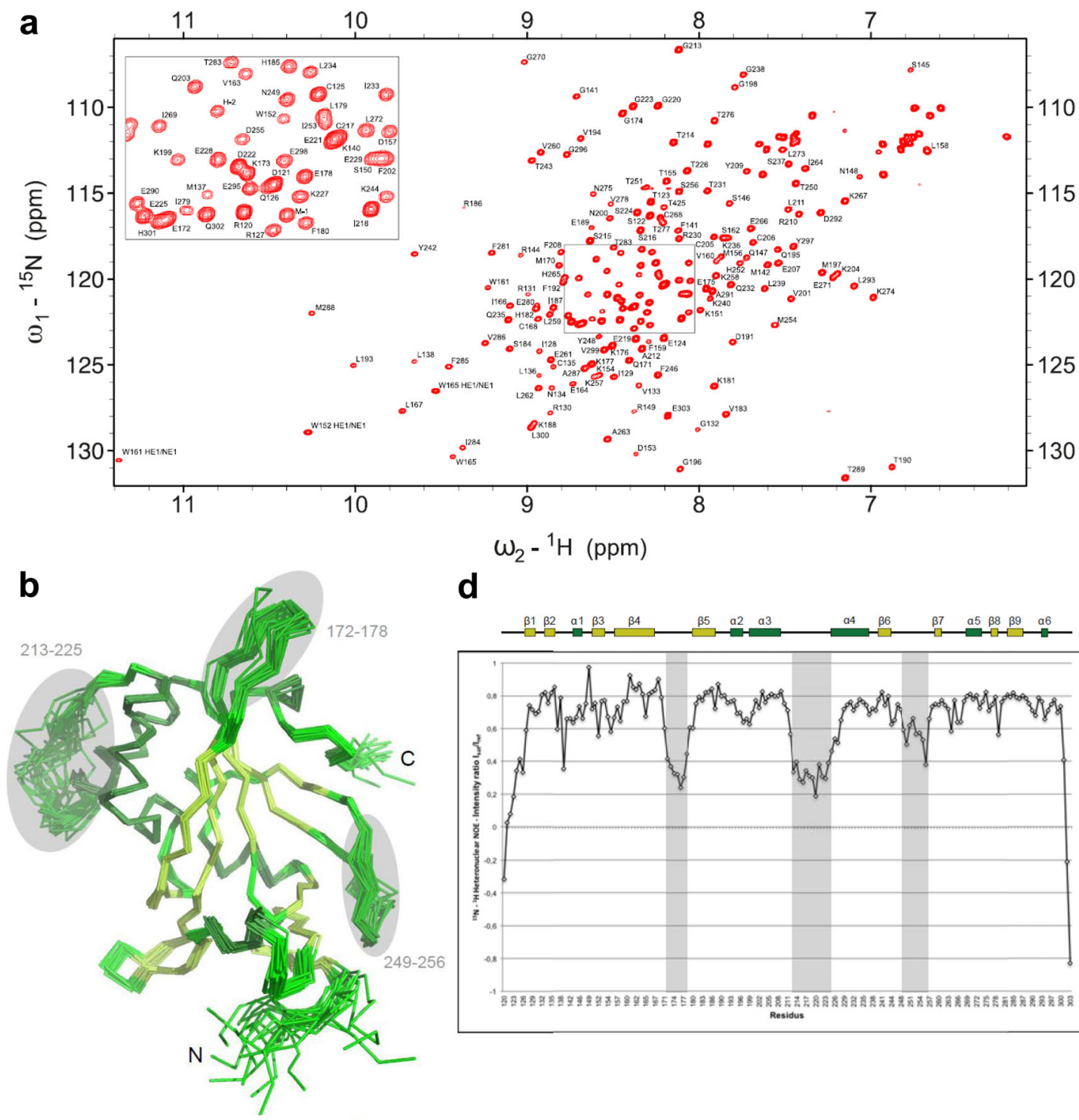

d
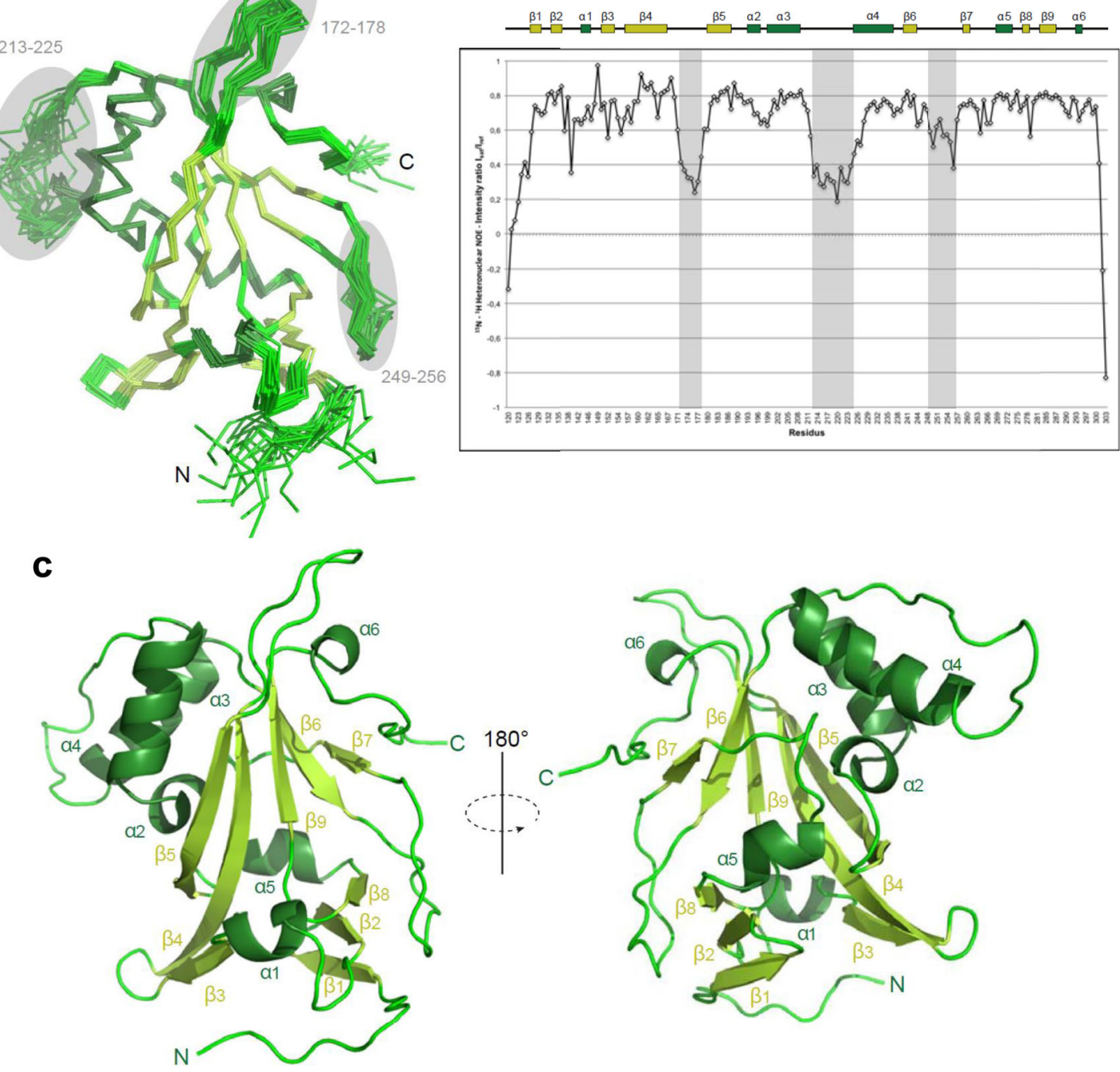

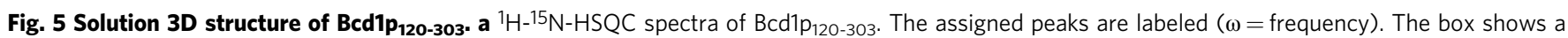
zoom of the center of the spectra. $\mathbf{b}$ Ribbon representation of the 20 best NMR solutions for the 3D structure of Bcd1p $120-303$. Flexible loops are circled in gray and labelled. Secondary structure elements are $\alpha$-helices (in dark green) and $\beta$-strands (in light green). $\mathrm{N}$ and $\mathrm{C}$ are the $\mathrm{N}$-terminal and $\mathrm{C}$-terminal extremities of the protein, respectively. c Two opposite views $180^{\circ}$ apart in a cartoon representation of Bcd1 $120-303$ with secondary structures labeled and numbered. The color code is the same as in panel b. d NMR heteronuclear nOe. Residue numbers are indicated at the bottom. Secondary structure elements are represented at the top in the same colors as in panel $\mathbf{b}$. The flexible internal regions are highlighted in gray, and reported in panel $\mathbf{b}$. 


\begin{tabular}{|c|c|}
\hline & Bcd1p $_{120-303}$ \\
\hline \multicolumn{2}{|l|}{$\begin{array}{l}\text { NMR distance and dihedral constraints } \\
\text { Distance constraints }\end{array}$} \\
\hline Total NOE & 4186 \\
\hline Intraresidue & 1115 \\
\hline Inter-residue & 3071 \\
\hline Sequential $(|i-j|=1)$ & 1087 \\
\hline Medium range $(|i-j| \leq 4)$ & 694 \\
\hline Long range $(|i-j| \geq 5)$ & 1290 \\
\hline Total dihedral angle restraints & 280 \\
\hline$\phi$ & 138 \\
\hline$\psi$ & 142 \\
\hline Total RDCs & 111 \\
\hline \multicolumn{2}{|l|}{ Structure statistics } \\
\hline \multicolumn{2}{|l|}{ Violations (mean and s.d.) } \\
\hline Distance constraints $(\AA)$ & $0.039 \pm 0.036$ \\
\hline Dihedral angle constraints $\left(^{\circ}\right)$ & $0.889 \pm 0.699$ \\
\hline Max. distance constraint violation $(\AA)$ & $0.24 \pm 0.04$ \\
\hline Max. dihedral angle violation $\left(^{\circ}\right)$ & $2.79 \pm 0.48$ \\
\hline \multicolumn{2}{|l|}{ Deviations from idealized geometry } \\
\hline Bond lengths $(\AA)$ & $0.0114 \pm 0.0003$ \\
\hline Bond angles $\left({ }^{\circ}\right)$ & $1.2036 \pm 0.0305$ \\
\hline Impropers $\left({ }^{\circ}\right)$ & $1.3914 \pm 0.0716$ \\
\hline \multicolumn{2}{|l|}{ Average pairwise r.m.s. deviationa $(\AA)$} \\
\hline Backbone & $0.74 \pm 0.16$ \\
\hline Heavy & $1.36 \pm 0.20$ \\
\hline
\end{tabular}

aPairwise r.m.s. deviation (residues 123-301) was calculated among 20 refined structures.

and folded subfragments (Supplementary Fig. 4 and Supplementary Fig. 5), it could be considered as an independent module, packed on the edge of Bcdl1 $p_{150-303}$, mainly via a $\beta$-sheet involving strands $\beta 1, \beta 2$, and $\beta 8$. With the exception of the $\mathrm{N}$ - and C-terminal tails of $\mathrm{Bcdl} \mathrm{p}_{120-303}$, the analysis of the ${ }^{1} \mathrm{H}-{ }^{15} \mathrm{~N}$ heteronuclear nOe ratios revealed three flexible regions (172-178, 213-225, and 249-256) related to large loops in the structure (Fig. 5b, d).

General view of the crystal structure of the Bcd1p $p_{120-303}$ : Rtt106 $\mathbf{p}_{65-301}$ heterocomplex. To understand the mode of interaction of $\mathrm{Bcd} 1 \mathrm{p}_{120-303}$ with $\mathrm{Rtt} 106 \mathrm{p}_{65-301}$, we characterized the $3 \mathrm{D}$ structure of the complex using X-ray crystallography (Fig. 6). The final structure was refined against the dataset collected from a native crystal to an $R_{\text {factor }}$ of $21.0 \%$ and an $R_{\text {free }}$ of $29.7 \%$, including all reflections between 20 and $2.79 \AA$ resolution (Table 2). The asymmetric unit contains one Bcdlp $p_{120-303}$ : Rtt106 $\mathrm{p}_{65-301}$ heterodimer.

The three loops in bound Bcdlp encompassing residues 173-177, 211-224, and 248-252, respectively, were not built due to the lack of density explained by their high flexibility in their native free state (Figs. 5d and 6a). Comparison of the crystal structure of Bcd1 $p_{120-303}$ bound to Rtt106 $\mathrm{p}_{65-301}$ with the NMR structure of Bcdlp $\mathrm{p}_{120-303}$ in a free state yielded a root-mean-square deviation (RMSD) of $\mathrm{Ca}$ positions of $1.13 \AA$. Indeed, the two 3D structures closely resembled one another and $3 \mathrm{D}$ superimposition revealed that no significant conformational modifications of Bcd1 $p_{120-303}$ occurred upon binding to Rtt106 $p_{65-301}$.

The overall structure of bound Rtt106 $\mathrm{p}_{65-301}$ displayed the tandem PH domain architecture as previously described ${ }^{22,26,46}$ with a large intramolecular interface between the first (PH1) and second (PH2) domains (Fig. 6a and Supplementary Fig. 7).
The loop that connects the $\beta$-strands S4 and S5 (residues 119-120) in the PH1 domain and the peptide link between the two $\mathrm{PH}$ domains (residues 206-217) were not present in the final crystal structure because of the lack of density and are possibly disordered in their native state. The overall fold of Rtt106 $\mathrm{p}_{65-301}$ bound to $B c d 1 p_{120-303}$ resembles that of $\mathrm{Rtt} 106 \mathrm{p}_{65-301}$ in free state 22 (entry PDB code 3TW1 [https://www.rcsb.org/structure/ 3TW1]), with a $0.95 \AA$ RMSD for $202 \mathrm{Ca}$ atoms. However, several local conformational changes, with structural deviations that can reach $4 \AA$, occurred in the $\mathrm{PH} 1$ domain upon binding of Bcd1p $p_{120-303}$ (Fig. 6b and Supplementary Fig. 8). For instance, some structural modifications occurred in the N-terminal part of the PH1 domain and were identified in the C-terminal part of $\beta$-strand $\mathrm{S} 1$, in the $\mathrm{N}$-terminal part of $\beta$-strand $\mathrm{S} 2$ and in the loops connecting $\beta$-strands S2 to S3, and S3 to S4. Two major conformational changes were observed in the $\mathrm{C}$-terminal part of the PH1 domain that involve $\alpha$-helices $\mathrm{H} 1$ and $\mathrm{H} 2$ as well as the loop connecting these two $\alpha$-helices. We concluded that the conformational changes induced by complex formation mostly occurred in Rtt106p.

Bcd1p 120-303 interacts with the domain PH1 of Rtt106p. The crystal structure of the Bcd1 $1 p_{120-303}:$ Rtt106 $p_{65-301}$ complex revealed that Rtt106p interacts with Bcdlp only via its PH1 domain (Fig. 6a). Most of the residues from Rtt106p that are buried upon interaction with Bcdlp are located in two distinct parts (Fig. 6c), including residues of the first S1 and S2 $\beta$-strands, solvent-exposed residues from the contiguous $\alpha$-helices $\mathrm{H} 1$ and $\mathrm{H} 2$, and residues from the loop connecting these two $\alpha$-helices. For Bcdlp, the interaction interface mainly involved the solventexposed faces of helix $\alpha 1$ and of strand $\beta 6$ located on one edge of the central $\beta$-strand (Fig. 6d). This observation reinforces the major role we already highlighted for the region 120-149 of Bcd1p in holding its helix al (Supplementary Fig. 4 and Supplementary Fig. 5). In addition, the $\mathrm{N}$-terminal parts of strands $\beta 8$ and $\beta 10$ of Bcdlp as well as the loop upstream from strand $\beta 9$ were partially buried upon binding to Rtt106 $\mathrm{p}_{65-301}$. A hydrophobic cluster formed at the heterodimer interface with side-chain interactions of four hydrophobic residues from each protein (Fig. 6e). Moreover, an ionic network involved positively charged residues from Bcdlp and negatively charged residues from Rtt106p (Fig. 6f). This observation is in accordance with the electrostatic potential mapped on the molecular surface of Bcdlp 120-303 $_{12}$ (Supplementary Fig. 9). Finally, many hydrogen bonds involving main chains atoms were also observed (Fig. $6 \mathrm{~g}$ ).

Structural MS characterization in solution of Bcdlp $\mathrm{p}_{\mathrm{FL}}$ : Rtt106p-M. We used alternative approaches to characterize complexes containing the full-length $\mathrm{Bcd} 1$ protein $\left(\mathrm{Bcd} 1 \mathrm{p}_{\mathrm{FL}}\right)$ based on mass spectrometry. First, we used hydrogen deuterium exchange coupled with mass spectrometry (HDX-MS) to characterize the conformational dynamics of $\mathrm{Bcd} 1_{\mathrm{FL}}$ and Rtt106p-M proteins upon the complex formation. HDX enables identification of regions that either are protected from the solvent upon complex formation or undergo conformational changes resulting in differences in solvent accessibility ${ }^{47}$. We consequently compared the deuterium incorporations of the Bcd1 $\mathrm{p}_{\mathrm{FL}}$ :Rtt106p-M complex to those of the isolated partners (Fig. 7). Concerning the impact of Rtt106p-M binding on $\mathrm{Bcd} 1 \mathrm{p}_{\mathrm{FL}}$, the $\mathrm{N}$-terminal region of Bcd1 $1 p_{1-125}$ was not much affected upon Rtt106p-M binding (Supplementary Fig. 10a and Supplementary Fig. 11). Moreover, Bcdlp showed significant protection upon the complex formation for regions 125-202; 218-234, and 242-281, encompassing respectively, strands $\beta 1$ to $\beta 5$ and helices $\alpha 1-\alpha 2$; helix $\alpha 4$; helix $\alpha 5$ and strands $\beta 7$ to $\beta 8$ (Supplementary Fig. 7a, Supplementary 
a

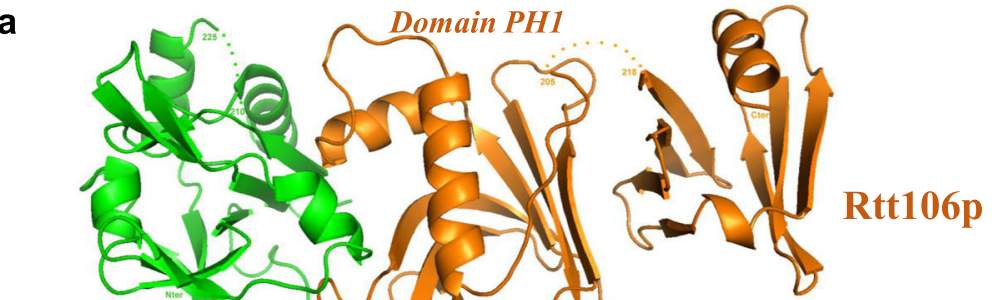

Bed1p

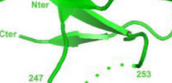

T 8

Domain PH2

b

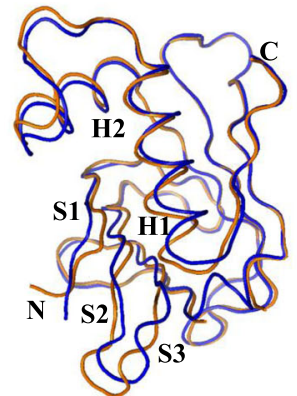

c

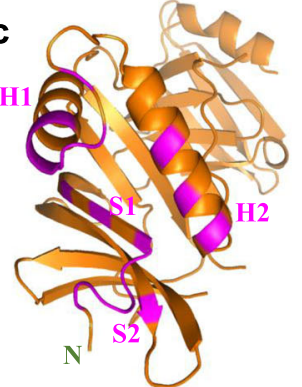

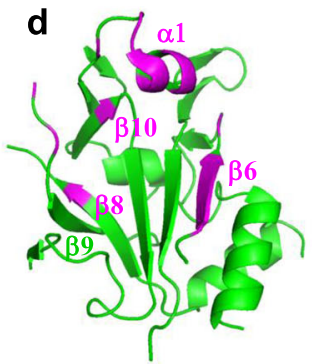

e

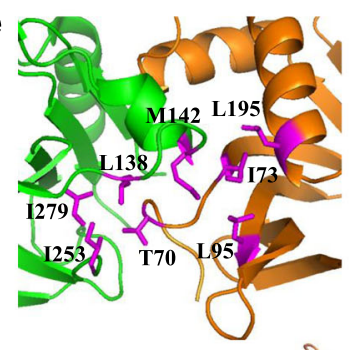

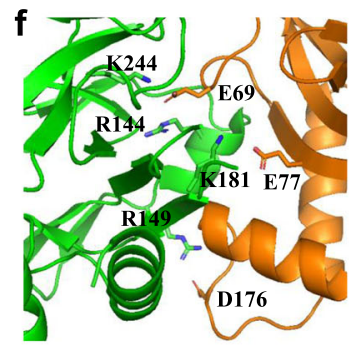
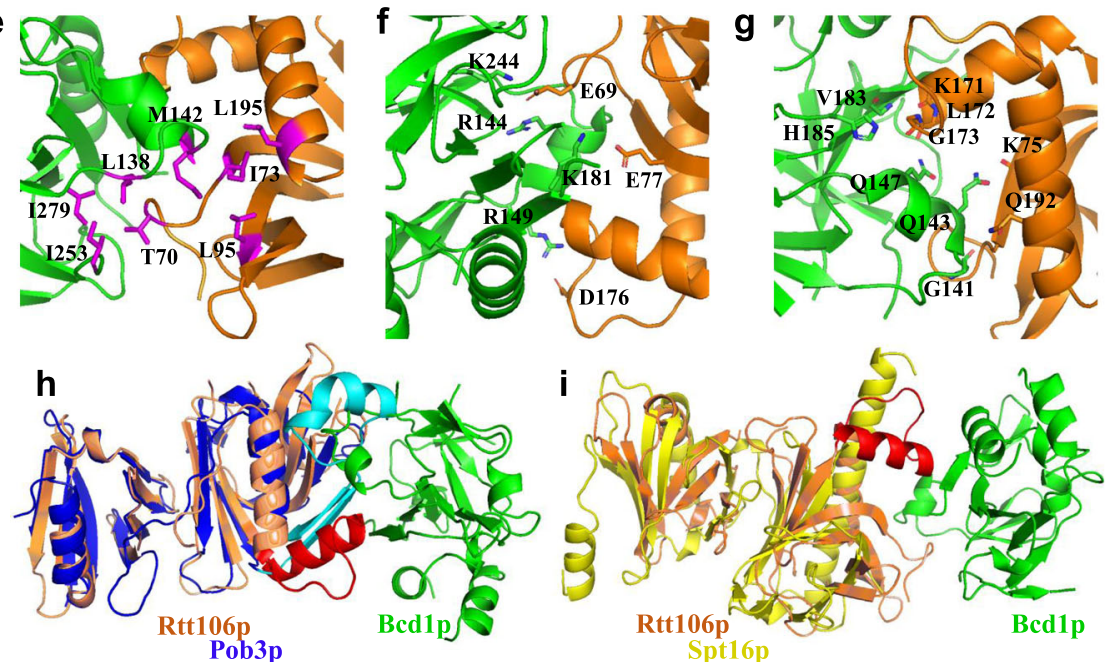

Fig. 6 Bcd1 $\mathbf{B}_{\mathbf{1 2 0 - 3 0 3}}$ interacts with the PH1 domain of $\mathbf{R t t}_{\mathbf{1 0 6}} \mathbf{p}_{\mathbf{6 5 - 3 0 1}}$. a Ribbon representation of the crystal structure of the complex between Rtt106 $\mathrm{p}_{65-301}$ and $\mathrm{Bcd1} 1 \mathrm{p}_{120-303}$. Rtt106p is in orange and Bcd1p in green. $\mathbf{b}$ Superimposition of the PH1 domain of Rtt106p bound to Bcd1p (in orange) and in a free state (in blue, entry PDB code 3TW122 [https://www.rcsb.org/structure/3TW1]). H=Helix, S = Strand, N=N-terminal extremity, C = C-terminal extremity. c Residues located at the molecular surface of Rtt106p that are buried upon Bcd1p binding are in magenta. $\mathbf{d}$ Residues located at the molecular surface of Bcd1p that are buried in the Rtt106p:Bcd1p interface are in magenta. e-g Hydrophobic contacts, salt-bridges, and hydrogen bonds at the Rtt106p:Bcd1p interface: $\mathbf{e}$ Hydrophobic cluster (magenta) at the interface of the heterodimer. $\mathbf{f}$ Charged residues located at the interface form ionic interactions between Rtt106p and Bcd1p. $\mathbf{g}$ Network of hydrogen bonds between Rtt106p and Bcd1p. $\mathbf{h}, \mathbf{i}$ Comparison of the 3D structures of Pop3p (in blue, entry PDB code 4PQ0 [https://www.rcsb.org/structure/4PQ0]) and Spt16p (in yellow, entry PDB code 4IOY [https://www.rcsb.org/structure/4IOY]). The sequence spanning amino acids 162-182 in Rtt106p, which differs strongly from Pob3p and Spt16p, is in red.

Fig. 10a and Supplementary Fig. 11). While helix $\alpha 1$ was shown to be involved in the interaction (Fig. $6 \mathrm{~d}$ ), the $\beta$ sheet composed of strands $\beta 1, \beta 2$, and $\beta 8$ showed strong protection upon Rtt106p-M binding (Fig. 7, Supplementary Fig. 10a and Supplementary Fig. 11), highlighting a higher stability of this region. Interestingly, region 208-217 (not built in the crystal structure), spanning the C-terminal part of helix $\alpha 3$ and part of the loop $\alpha 3$ - $\alpha 4$ showed higher deuterium uptake in presence of Rtt106p-M, highlighting a higher flexibility of this region upon the complex formation. The same analysis was performed on Rtt106p-M and highlighted several regions that were affected upon the complex formation (Fig. 7, Supplementary Fig. 10b and Supplementary Fig. 12). Firstly, regions $75-80$ and 94-106 encompassing $\beta$-strands S1, the C-terminal part of S2 and S3 (Supplementary Fig. 7b) showed protection upon Bcdlp $\mathrm{FL}$ binding. Furthermore, protection was also identified for regions 126-137; 148-175, and 188-233 spanning respectively $\beta$-strands S5, S7 and $\alpha$-helix H1; the C-terminal part of $\alpha$-helix $\mathrm{H} 2$ and $\beta$-strands S8 and S9. Interestingly, strands S7, S8, and S9 are at the interface of domains $\mathrm{PH} 1$ and $\mathrm{PH} 2$. The variations observed in these regions are probably due to the relative intramolecular flexibility between these two domains while strands S1, S2 and helices $\mathrm{H} 1$ and $\mathrm{H} 2$ were shown to be involved in the interaction with Bcd1p (Fig. 6c).

Next, we performed chemical cross-linking experiments followed by mass spectrometry (XL-MS) to identify potential intercross-linked peptides and assess amino-acid residues of 


\begin{tabular}{|c|c|}
\hline & Bcd1p $_{120-303}:$ Rtt106p $65-301$ \\
\hline \multicolumn{2}{|l|}{ Data collection } \\
\hline Space group & $P 2_{1}$ \\
\hline \multicolumn{2}{|l|}{ Cell dimensions } \\
\hline$a, b, c(\AA)$ & $56.71,66.68,65.12$ \\
\hline$\alpha, \beta, \gamma\left({ }^{\circ}\right)$ & $90.00,104.72,90.00$ \\
\hline Resolution $(\AA)^{a}$ & $50-2.79(2.79-2.95)$ \\
\hline$R_{\text {sym }}$ & $4.7(23.3)$ \\
\hline$|/ \sigma|$ & $27.4(6.7)$ \\
\hline Completeness (\%) & $99.1(96.7)$ \\
\hline Redundancy & $6.7(6.4)$ \\
\hline \multicolumn{2}{|l|}{ Refinement } \\
\hline Resolution $(\AA)$ & $20-2.79$ \\
\hline No. reflections & 10,224 \\
\hline$R_{\text {work }} / R_{\text {free }}$ & $0.210 / 0.297$ \\
\hline \multicolumn{2}{|l|}{ No. atoms } \\
\hline Protein & 3007 \\
\hline Ligand/ion & - \\
\hline Water & - \\
\hline \multicolumn{2}{|l|}{$B$-factors } \\
\hline Protein & 58.0 \\
\hline Ligand/ion & - \\
\hline Water & - \\
\hline \multicolumn{2}{|l|}{ R.m.s. deviations } \\
\hline Bond lengths $(\AA)$ & 0.014 \\
\hline Bond angles $\left({ }^{\circ}\right)$ & 1.733 \\
\hline
\end{tabular}

proximity. The resulting peptide fragments were analyzed to look for intermolecular cross-links present as doublets peaks of heavy BS3-d4 and light BS3-d0 modified peptides. Interestingly, a total 11 intramolecular cross-linked peptides of $\mathrm{Bcdl} \mathrm{p}_{\mathrm{FL}}$ and one intermolecular cross-linked peptide involving $\mathrm{K}_{151}$ of $\mathrm{Bcd} 1 \mathrm{p}_{\mathrm{FL}}$ and $\mathrm{S}_{177}$ of Rtt106p-M were identified and validated (Fig. 7, Table 3 and Supplementary Table 2). Of note, no intra XL peptides were manually validated for Rtt106p-M, mostly because only the heavy BS3-d4 cross-link peptide was detected in the experiments. $K_{151}$ of Bcdlp $p_{F L}$ and $S_{177}$ of Rtt106p-M residues are located at the dimer interface of the complex: while Bcdlp $\mathrm{K}_{151}$ residue is part of the strand $\beta 3, S_{177}$ residue of Rtt106p is part of the loop between helices $\mathrm{H} 1$ and $\mathrm{H} 2$, and neighbor residues directly involved in the ionic and hydrogen bond networks (Fig. 7, Supplementary Fig. 7 and Fig. 6f, g). Thus, HDX and chemical XL-MS results showed remarkable agreement among themselves and with the previous structural characterization of the complex. Besides, HDX allowed to highlight conformational dynamics of the proteins and particularly for Bcdlp, showing a strong impact upon the complex formation for additive region, especially the $\beta 1-\beta 2-\beta 8$ sheet, which showed a strong protection.

3D model of a potential Bcd1p:Rtt106p:(H3:H4) $)_{2}$ complex. Deposition of newly synthesized H3:H4 complex on replicating DNA relies on the interaction of Rtt106p with histone $\mathrm{H} 3: \mathrm{H} 4$ tetramers and requires acetylation of $\mathrm{H} 3$ lysine $56^{22}$. To explore whether Bcdlp could interfere in the formation of the Rtt106p:(H3:H4) $)_{2}$ complex, we built a 3D model of the heterodimer Rtt106 $\mathrm{p}_{65-301}: \mathrm{Bcdl}_{120-303}$ bound to the histone tetramer (H3:H4) $)_{2}$, on the basis of the 3D model established for Rtt106p: $(\mathrm{H} 3: \mathrm{H} 4)_{2}{ }^{22}$ and the present crystal structure of Rtt106 $\mathrm{p}_{65-301}$ : Bcd1 $p_{120-303}$ (Supplementary Fig. 13a). In this model, the binding of Bcdlp $120-303$ appears to be compatible with the structure of Rtt106p:(H3:H4) ${ }_{2}$ complex as histones $\mathrm{H} 3: \mathrm{H} 4$ and Bcdlp have

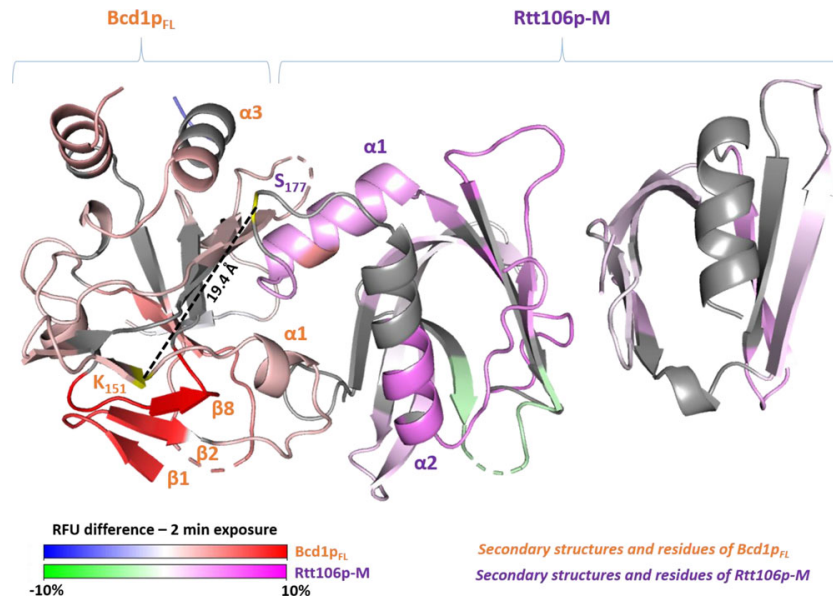

Fig. 7 Summary of the XL-MS and HDX-MS experiments. Relative fractional uptake (RFU) differences export on the crystal structure of the complex between Rtt106p-M and Bcd1 $\mathrm{p}_{\mathrm{FL}}$ determined by hydrogen deuterium exchange mass spectrometry (HDX-MS). Export is realized for 2 min deuteration experiments. Differences are color scaled on Bcd1 $\mathrm{p}_{\mathrm{FL}}$ from blue (deprotection) to red (protection) upon Rtt106p-M binding ( $-10 \%$ to 10\% RFU difference range). Differences are color scaled on Rtt106p-M from green (deprotection) to magenta (protection) upon Bcdlp $\mathrm{F}_{\mathrm{FL}}$ binding ( $-10 \%$ to $10 \%$ RFU difference range). The $\mathrm{C} \alpha$-C $\alpha$ distances of intercrosslinked peptides are represented with black dotted lines. Orange residues and secondary structures represent the most affected regions on $\mathrm{Bcd} 1 \mathrm{p}_{\mathrm{FL}}$ while the purple ones represent the most affected regions on Rtt106p-M.

distinct interaction regions on Rtt106p. We also performed ITC measurements with an acetylated peptide (H3K56ac) known to interact with the PH2 domain 22 . Our data showed similar interaction modes between $\mathrm{H} 3 \mathrm{~K} 56 \mathrm{ac}$ and the free form of Rtt106 $\mathrm{p}_{65-301}$ or the form bound to Bcd1 $\mathrm{p}_{120-303}$ (Supplementary Fig. 13b). Affinities and thermodynamic values in both experiments were of the same order of magnitude. We concluded that Rtt106 $\mathrm{p}_{65-301}$ can simultaneously interact with $B c d 1 p_{120-303}$ and the H3K56ac peptide.

\section{Discussion}

Here, we report on a link between the machinery involved in box C/D snoRNP assembly and the machinery for chromatin assembly and remodeling. Genetic interaction mapping (GIM) analysis performed with the query mutation strain disrupted for the snoRNP assembly factor Rsalp revealed an epistatic effect with several genes involved in chromatin remodeling, including histone chaperones (Fig. 1). We observed that one of these histone chaperones-Rtt106p-directly binds Bcdlp (Fig. 2), another RNP assembly factor that is crucial for box C/D snoRNP assembly and cell growth. The selective interaction of Rtt106p with Bcd1p relies on a structural motif absent in other structurally related histone chaperones Pob3p and Spt16p ${ }^{22,26,39,40}$ (Fig. 6h, i). No clear homolog of Rtt106p has been identified in human, but the Rtt106p binding domain (RBD, Fig. 2a) in Bcdlp is conserved in human and mouse ${ }^{13}$ (Supplementary Fig. 6a), and in other yeasts including pathogenic Candida species (Supplementary Fig. 6b). Our structural studies revealed the 3D structure of this interaction domain spanning amino acids 120-303 (Fig. 5b and Fig. 6a). Structural MS analysis and our X-ray structure of Bcdlp $_{120-303}: \mathrm{Rtt}_{106 \mathrm{p}_{65-301}}$ indicated that the region spanning amino acids 120-149 drives the interaction with the PH1 domain of Rtt106p. Using the Dali server ([http://ekhidna.biocenter. helsinki.fi/dali_server]), the wheel domain of the protein Cns1 was retrieved as the best $3 \mathrm{D}$ homolog of $\mathrm{Bcd} 1 \mathrm{p}_{120-303}$. This result 
Table 3 Cross-linked sites observed with different protein:BS3 (d0/d4) ratios for the complex Bcd1p

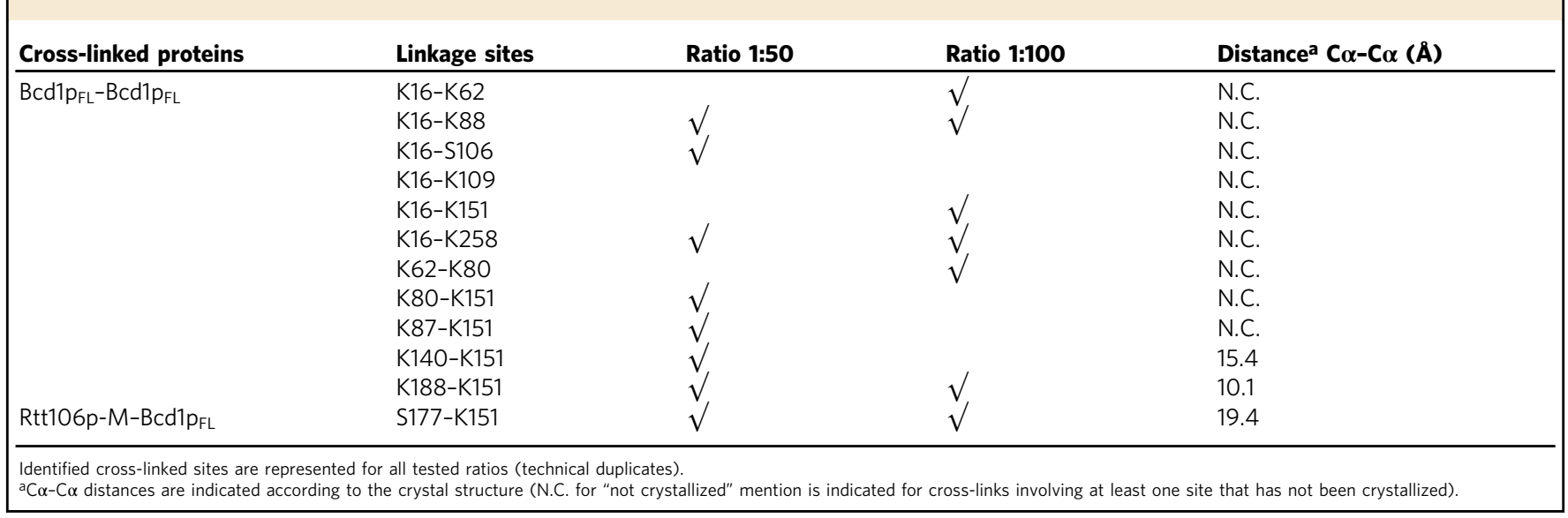

confirms recent predictions about the presence of a wheel domain in $\operatorname{Bcd} 1 \mathrm{p}^{13}$. When aligned, these two homologs showed structural similarities, especially in the organization of the $\beta$-strands, despite low amino-acid sequence conservation (Supplementary Fig. 14). Interestingly, region $150-303$ in $\mathrm{Bcd} 1 \mathrm{p}$, which encompasses the core $\beta$-sheet formed with strands $\beta 3-\beta 7$ and $\beta 9$, preferentially aligns with the wheel domain of Cns1p, especially with strands $\beta 2$ to $\beta 6$. Cnslp has been described as a co-chaperone of Hsp90, assisting the folding of the elongation factor eEF2 ${ }^{48}$. One can thus assume that Bcdlp adopts similar functions via its region 150-303, which is mainly free of interactions with Rtt106p.

In agreement with data resulting from the GIM analysis, it has already been suggested that Rsalp is connected with chromatin dynamics. Rsalp and its binding partner Hitlp were shown to contribute to condensin Brn1p accessibility to rDNA and to delay rDNA compaction during the cell cycle, thereby enabling the coordination of nucleolar segregation with mitotic exit ${ }^{49}$. The mechanism of action of Rsalp:Hitlp in the control of rDNA compaction is not known, but the role of snoRNP assembly factors associated with chromatin regulation nevertheless appears to be conserved. Indeed, mitotic exit in Schwan cells involves ZNHIT3, the counterpart of Hitlp in human ${ }^{50}$. Since rsals leads to chromatin hypercondensation ${ }^{49}$, it is possible that mutations that affect actors of DNA condensation compensate for the negative effect of $r s a 1 \Delta$ and increase the fitness of mutant cells, as selected in the GIM approach. We thus favor the hypothesis of a suppressive effect when $r s a 1 \Delta$ is combined with the disruption of RTT106 (rtt106 $\Delta$ ) or with the disruption of genes encoding components of the chromatin remodeling complexes HIR, INO80, and CAF-1.

At first glance, the characterization of a Bcd1p:Rtt106p complex suggested that Rtt106p could have a function in snoRNP assembly, and/or that Bcdlp regulates the activity of Rtt106p in the control of chromatin structure, and/or that the Bcd1p:Rtt106p complex contributes to another cellular mechanism. The present work did not reveal any strong involvement of Rtt106p in the function of Bcdlp in snoRNP biogenesis under standard laboratory culture conditions. Indeed, under these conditions, the disruption of RTT106 (Supplementary Fig. 2b) had no major effect on the steady-state levels of snoRNAs. We previously identified the $\mathrm{N}$-terminal region as necessary for $\mathrm{Bcd} 1 \mathrm{p}$ function and it did not correspond to the region involved in Rtt106p interaction $^{12}$. Nonetheless, we show that the histone chaperone Rtt106p is present on box C/D snoRNAs including pre-snoRNAs (Fig. 3a) and remarkably also at snoRNA gene loci (Fig. 3b). The specificity of the association of Rtt106p with pre-snoRNAs was confirmed by the observation that it requires the presence of
Bcdlp and the Snu13p-interacting protein Rsal ${ }^{51}$ (Fig. 3a) Hence, Rtt106p is likely recruited to snoRNAs by binding Bcd1p, which is either present in a pre-existing pre-snoRNA:Snu13p: Rsa1p:Bcd1p RNPs or in a protein-only complex before its loading to RNA. However, in both scenarios, binding could occur during preparation of the cell extract thereby explaining why no contribution of Rtt106p to the biogenesis of snoRNPs was observed. Nonetheless, it is possible that under specific growth conditions, association of Rtt106p with pre-snoRNP contributes to or regulates snoRNP biogenesis.

Can Bcd1p regulate Rtt106p activity? Rtt106p contributes to the formation of nucleosome on replicating $\mathrm{DNA}^{22-26}$ but is also linked to transcription activity ${ }^{29}$. During the replicationdependent process, new $(\mathrm{H} 3: \mathrm{H} 4)$ dimers present in a nuclear heterotrimeric complex Asf1p:(H3:H4) are transferred to CAF-1 and Rtt106p for formation and deposition of $(\mathrm{H} 3: \mathrm{H} 4)_{2}$ tetramers onto newly synthesized $\mathrm{DNA}^{52}$. Less information is available on the mode of action of Rtt106p for nucleosome disassembly associated with transcription initiation and nucleosome reassembly in the wake of RNA polymerase compared to the documented activities of FACT, Rtt109p, and Asflp in such processes ${ }^{45,53}$. Rtt106p interacts functionally and genetically with various regulators of RNA polymerase II transcription ${ }^{43,54-56}$ and is physically associated with transcribed chromatin regions ${ }^{29}$. Our ChIP analysis confirmed enrichment of Rtt106p in the body of active genes including the U3 snoRNA locus (SNR17A, Fig. 3b, c). Remarkably, a co-immunoprecipitation assay revealed a robust association between Rtt106p and Rpb1p, the largest subunit of RNA polymerase II (Fig. 4a). This observation suggests that enrichment of Rtt106p to these loci is RNA polymerase IIdependent and thus identifies histone chaperone Rtt106p as an actor involved in chromatin control during transcription, as primarily proposed ${ }^{29}$. Whether Rtt106p provides $\mathrm{H} 3: \mathrm{H} 4$ for nucleosome assembly by traveling with elongating RNA polymerase II complexes or afterwards is still an open question. The identification of the Rtt106p:Rpblp interaction favors the first hypothesis.

Most importantly, the present data reveal that $\mathrm{Bcd} 1 \mathrm{p}$ reduces the association between Rtt106p and the RNA polymerase II as well as the enrichment of H3K56ac marks to several transcriptionally active genes (Fig. 4). Therefore, the data strongly suggest that, by direct interaction with Bcd1p, Rtt106p dissociates from the RNA polymerase machinery that allows its recruitment and function at actively transcribed genes.

We propose that the control of Rtt106p activity by Bcd1p is not performed on chromatin, at the site of transcription. Originally, it was suggested that Rtt106p must interact with DNA to deliver 
histones $\mathrm{H} 3: \mathrm{H} 4$ during replication ${ }^{30}$ and a conserved positively charged surface of Rtt106p was shown to be responsible for dsDNA binding ${ }^{30,46}$. First, in the crystal Bcdlp:Rtt106p complex (Fig. 6), the binding site for dsDNA at the surface of Rtt106p is still exposed to the solvent and a second positive patch continuing the one of Rtt106p is present on the surface of Bcdlp (Supplementary Fig. 15). In addition, the 3D model of the heterodimer Rtt106 $\mathrm{p}_{65-301}: \mathrm{Bcdl}_{120-303}$ bound to the histone tetramer (H3: $\mathrm{H} 4)_{2}$ (Supplementary Fig. 13a) also predicts absence of direct interference of Bcdlp in Rtt106p activity for the nucleosome assembly. Second, we observed the same positive effect of Bcdlp depletion on Rtt106p enrichment at transcribed loci where Bcdlp was not enriched (Fig. 3b and Supplementary Fig. 2e). Indeed, the enrichment of Bcdlp to snoRNA loci observed in the ChIP experiment corresponds to the presence of Bcdlp on nascent presnoRNAs, as evidenced by the loss of enrichment upon RNase treatment ${ }^{12}$. Interestingly, we found that the association of Rtt106p at chromatin is partially sensitive to RNase treatment at both transcribed and nontranscribed loci (Supplementary Fig. 2e); the underlaying mechanism is unknown but we determined that it was independent from the effect generated by Bcd1p. It remains to be determined how the interaction of Bcdlp precludes the transcription-dependent recruitment of Rtt106p. We propose that Bcdlp could deplete Rtt106p from active loci by forming delocalized Bcd1p:Rtt106p complexes. Concerning the snoRNA loci, an attractive possibility would be that the interaction of Rtt106p with the nascent pre-snoRNPs containing Bcdlp could reduce the activity of Rtt106p during transcription at these loci. However, it is likely the free RNA-unbound form of the Rtt106p:Bcd1p complex that has a regulatory function and not the one associated with nascent pre-snoRNPs. Indeed, the modulation of Rtt106p association across the SNR17A gene encoding $\mathrm{U} 3$ is Rsalp-independent and consequently does not rely on the formation of the pre-snoRNP (Fig. 3b).

In conclusion, the present data reinforce the proposal that, in addition to its activity during replication, the chaperone Rtt106p contributes to chromatin structure during transcription elongation ${ }^{29}$. We identified a new interaction interface in its PH1 domain that binds Bcdlp, an essential factor for $\mathrm{C} / \mathrm{D}$ box assembly, and therefore for functional ribosome formation and cell proliferation ${ }^{10-13}$. The interaction between Rtt106p and Bcdlp we evidenced here may represent an important connection point to coordinate RNA polymerase II transcription activity and ribosome formation.

\begin{abstract}
Methods
Reagents. Ammonium acetate $\left(\mathrm{NH}_{4} \mathrm{Ac}\right), 4$ - $(2$-Hydroxyethyl)piperazine-1-ethanesulfonic acid (HEPES), tris(2-carboxyethyl)phosphine (TCEP), dibasic potassium phosphate $\left(\mathrm{K}_{2} \mathrm{HPO}_{4}\right)$, monobasic potassium phosphate $\left(\mathrm{KH}_{2} \mathrm{PO}_{4}\right)$, guanidine hydrochloride $(\mathrm{GuHCl})$, and hydrochloric acid $(\mathrm{HCl})$ were purchased from Sigma (St. Louis, MO, USA). Deuterium oxide $\left(\mathrm{D}_{2} \mathrm{O}\right)$ and deuterium chloride were purchased from Euriso-top (Saarbrücken, Germany). Bis(sulfosuccinimidyl) suberate d0/d4 (BS3-d0/d4) and Zeba column were purchased from Thermo Scientific (Rockford, IL, USA). Vivaspin cutoff $5 \mathrm{kDa}$ was purchased from Sartorius (Goettingen, Germany), Glu-fibrinogen peptide (GFP) from ERA (Golden, CO, USA), trypsin from Promega (Madison, WI, USA), and pepsin-immobilized cartridge from Applied Biosystems (Forster city, CA, USA). Protein samples were home produced. Oligonucleotides are listed in Supplementary Table 3.
\end{abstract}

Plasmids and strains. Plasmids are listed in Supplementary Table 4. The fragments of proteins Bcdl and Rtt106 used for biochemical and structural assays were overexpressed in E. coli BL21 pRARE2 grown in LB rich media and transformed with recombinant pnEA-3CH plasmid leading to expression of a $6 \times$ His-tag at the $\mathrm{N}$-terminal extremity of the protein followed by the PreScission protease cleavage site $^{57}$. In addition, for the co-expression assays, cells were transformed by the recombinant plasmid $\mathrm{pnCS}^{57}$.

All yeast strains were generated in the S. cerevisiae BY4741 background unless otherwise indicated (Supplementary Table 5). Genes were deleted by one-step integration of KO cassettes, followed by PCR verification of the 5' and 3' ends of targeted gene. GAL1 promoter or TAP tag was inserted by homologous recombination. Correct insertion at the locus was checked by PCR and sequencing.

Yeast two-hybrid assays. pGBKT7 plasmids expressing the bait protein fused to the DNA binding domain of Gal4 and pACTII expressing the prey protein fused to the transcription activation domain of Gal4 were used to transform haploid yeast cells Y187 and Y190, respectively. The transformed cells were selected on single selective medium lacking tryptophan $\left(\mathrm{Trp}^{-}\right)$for pGBKT7 and leucine $\left(\mathrm{Leu}^{-}\right)$for pACTII. After mating, the diploid cells containing both plasmids were selected on double selective medium Leu ${ }^{-} \mathrm{Trp}^{-}$and then plated on triple selective medium Leu $\mathrm{Trp}^{-} \mathrm{His}^{-}$in order to reveal expression of the reporter HIS3 gene. Increase concentration of 3-amino-1, 2, 4-triazol (3-AT) (Sigma), a competitive inhibitor of the product of HIS3, was used to evaluate the strength of the interaction between the bait and the prey proteins. Growth was assessed after three days of incubation at $30^{\circ} \mathrm{C}$.

Genetic interactions mapping (GIM). The method is described in detail elsewhere ${ }^{58,59}$. Here we describe the main principles of the different steps of the method. The query strain $r s a 1 \triangle:: p r M F \alpha 2 N a t^{R}$ was generated by changing the KanMX4 marker to the prMF $22 \mathrm{Nat}^{\mathrm{R}}$ marker in the knockout mutant Mat $\alpha$ strain BY4742 rsa1 $\Delta::$ KanMX4. The query strain was transformed with plasmid pG1D1 bearing hygromycin resistance and mated in mass with the pooled $M A T a$ yeast deletion library $\left(\operatorname{Kan}^{\mathrm{R}}\right)$ comprising 4885 S. cerevisiae mutants from the systematic collection of haploid deletion strains and 977 barcoded haploid DAmP (decreased abundance by mRNA perturbation) strains in which the function of essential genes was perturbed by the introduction of a drug resistance cassette downstream from the stop codon, leading to an extended 3' UTR ${ }^{32}$. The diploids were selected for hygromycin and kanamycin resistance. After sporulation, the Mat $\alpha$ double mutant haploids cells were directly selected for combined nourseothricin and kanamycin resistance in standard rich liquid medium (YPD) and grown at constant turbidity for 18 generations. The relative measured fitness of the double mutants $\log 2(\mathrm{Q} / \mathrm{R})$ was estimated from the values of the intensity of hybridization signal on custom glass slide oligonucleotide microarrays (custom Agilent, GEO GPL18088) for the query double mutant population $(\mathrm{Q})$ compared with a reference double mutant population obtained in parallel (R). Hybridizations were performed with fragments obtained by amplification of the tags by PCR with Cy3 and Cy5 5'-end-labeled oligonucleotides.

Protein co-immunoprecipitation (co-IP) and RNA immunoprecipitation (RIP) assays. Yeast cells were grown at $30^{\circ} \mathrm{C}$ in YPD to $\mathrm{A}_{600} \sim 0.8-1$. After centrifugation, cell pellets were resuspended in breaking buffer (HEPES-KOH $20 \mathrm{mM}$ (pH 7.9); $\mathrm{NaCl} 150$ mM; $\mathrm{MgCl}_{2} 3 \mathrm{mM}$; DTT 0.5 mM, TRITON-X-100 0.1\%; Glycerol 10\%; Antiproteases $1 \times$ (Thermo Scientific) and lysed by bead-beating. The lysate was then clarified twice by centrifugation at $6,000 \times \mathrm{g}$ for $5 \mathrm{~min}$. The yeast cell extract was incubated, depending on the tagged protein, either with protein $G$ magnetic beads (Invitrogen) coupled with anti-HA 3F10 antibodies (Roche) at dilution $1 / 40$, or with IgG-Sepharose beads (GE Healthcare), or with ANTI FLAGM2 agarose beads (Sigma) for $2 \mathrm{~h}$ at $4{ }^{\circ} \mathrm{C}$. The beads were washed three times in breaking buffer. Proteins retained on beads were extracted by boiling in $1 \times$ Laemmli buffer (2\% SDS, $10 \%$ glycerol, 5\% 2-mercaptoethanol, $0.01 \%$ bromophenol blue and $60 \mathrm{mM}$ Tris-HCl, $\mathrm{pH} 6.8$ ), fractionated on 12.5\% SDS-PAGE and analyzed by Western blotting according to standard procedures using rabbit commercial Peroxidase Anti-Peroxidase (PAP) at dilution 1/2000 or monoclonal anti-HA antibodies (Roche) at dilution 1/250 and ECL Prime Western blotting system (GE healthcare). Anti-Dpslp (provided by C. Allmang and G. Eriani, IBMC, Strasbourg, France) was used at 1/5000 dilution to reveal loading controls For RIP experiments, RNAs retained on beads were extracted with phenolchloroform-isoamyl alcohol and analyzed by RT-qPCR. cDNAs were generated using M-MLV Reverse Transcriptase (Invitrogen) and random hexamers or oligonucleotide primers specific of pre-snoRNAs. Quantitative PCR using iTaq Universal SYBRGreen premix (Biorad) were performed on the STEPONE apparatus using a relative quantification and a standard curve method.

Chromatin immunoprecipitation (ChIP). Yeast cells grown as described above to the mi-log phase were fixed with $1 \%$ formaldehyde (10 $\mathrm{min}$ at room temperature), quenched with $0.125 \mathrm{M}$ glycine, and lysed by bead-beating in breaking buffer (see previous paragraph) and presence of $400 \mu \mathrm{L}$ glass beads (Sigma). Chromatin was sonicated to an average length of $200-500 \mathrm{bp}$ and incubated on a wheel at $4{ }^{\circ} \mathrm{C}$ during $60 \mathrm{~min}$ in solubilization buffer (50 mM HEPES-KOH (pH 7.5), $500 \mathrm{mM}$ $\mathrm{NaCl}, 1 \mathrm{mM}$ EDTA, $1 \%$ Triton X-100, 0.1\% Na-deoxycholate, 0.1\% SDS, Antiproteases $1 \times$ (Thermo Scientific)). FLAG-M2 Agarose FLAG-beads or protein G magnetic beads (Invitrogen) coupled with H3K56ac antibody (active motif) at dilution 1/50 for IP and 1/1000 for blotting were pre-cleared in breaking buffer containing $20 \mu \mathrm{g} / \mathrm{mL}$ BSA for $2 \mathrm{~h}$. Protein-DNA complexes were captured on beads for $2 \mathrm{~h}$ at $4{ }^{\circ} \mathrm{C}$, washed twice with low salt buffer (50 mM HEPES-KOH ( $\left.\mathrm{pH} 7.5\right)$, $50 \mathrm{mM} \mathrm{NaCl}, 1 \mathrm{mM}$ EDTA, $0.1 \%$ Triton X-100, $0.01 \%$ Na-deoxycholate, $0.05 \%$ SDS), followed by washes with $\mathrm{LiCl}$ buffer $(250 \mathrm{mM} \mathrm{LiCl}, 10 \mathrm{mM}$ Tris- $\mathrm{HCl}(\mathrm{pH} 8)$, $1 \mathrm{mM}$ EDTA, $0.01 \%$ Igepal, $0.05 \% \mathrm{Na}$-deoxycholate) and IPP150 buffer (10 mM Tris- $\mathrm{HCl}(\mathrm{pH} 8), 15 \mathrm{mM} \mathrm{NaCl}, 0.01 \%$ Igepal). After digestion with proteinase $\mathrm{K}$ 
( $20 \mu \mathrm{g} / \mu \mathrm{L}$ in IPP50 buffer), reversal of the cross-links by overnight incubation at 70 ${ }^{\circ} \mathrm{C}$ and elution, DNA was purified and quantified by qPCR using gene-specific primers. The ratio of DNA in the immunoprecipitated material to DNA in the input chromatin was calculated and normalized to control reactions made with strains that do not express tagged proteins or with protein $\mathrm{G}$ beads coupled with IgG antibodies.

Statistics and quantitative analyses. Data are reported as mean values plus standard error of the mean of a least three biological replicates. The significance level using a paired two-tailed Student's $t$-test was set to $P$ values ${ }^{*} P<0.05$, ${ }^{* *} P<$ 0.01 , and ${ }^{* * *} P<0.001$.

Expression and purification of recombinant proteins. Co-expression tests were carried out using the procedure previously described ${ }^{51}$. Briefly, the E. coli BL21 (DE3) cells supplemented with the pRARE2 plasmid were co-transformed with pnEA-3CH and pnCS plasmids carrying the sequences of interest. Growth was performed in $100 \mathrm{~mL} \mathrm{LB}$ medium overnight at $20^{\circ} \mathrm{C}$ after induction with $0.2 \mathrm{mM}$ IPTG (Isopropyl $\beta$-D-1-thiogalactopyranoside) when $\mathrm{OD}_{600}$ reaches 0.7 . Then, the cells were harvested by centrifugation, resuspended in $4 \mathrm{~mL}$ high salt buffer $(25$ $\mathrm{mM}$ HEPES pH 7.5, $400 \mathrm{mM} \mathrm{NaCl}, 10 \mathrm{mM}$ Imidazole) and lysed by sonication. The lysate was centrifuged $30 \mathrm{~min}$ at $4{ }^{\circ} \mathrm{C}$ at $16,100 \times g .250 \mu \mathrm{L}$ of $50 \%$ slurry beads (TALON Superflow, GE Healthcare) were added to the supernatant and incubated for $1 \mathrm{~h}$ at $4^{\circ} \mathrm{C}$. After centrifugation $5 \mathrm{~min}$ at $700 \times \mathrm{g}$, the supernatant was discarded, and the beads were washed three times with $500 \mu \mathrm{L}$ of high salt buffer. Finally, a sample of the beads was mixed with $2 \times$ blue denaturing loading buffer to be analyzed by SDS-PAGE.

For preparation of protein for NMR experiment, bacteria transformed with expression vectors were grown at $37^{\circ} \mathrm{C}$ under agitation until $0.6<\mathrm{OD}_{600 \mathrm{~nm}}<1.0$ and protein overexpression was induced with $0.3 \mathrm{mM}$ of IPTG (Isopropyl $\beta$-D-1thiogalactopyranoside) at $20^{\circ} \mathrm{C}$ overnight. The protein $\mathrm{Bcd} 1_{120-303}$ was produced with non-deuterated or $100 \%$ deuterated M9 minimum medium containing $\left[{ }^{13} \mathrm{C}\right]-$ glucose $(2 \mathrm{~g} / \mathrm{L})$ and $\left[{ }^{15} \mathrm{~N}\right]-\mathrm{NH}_{4} \mathrm{Cl}(1 \mathrm{~g} / \mathrm{L})$ as nutrient sources. Cells were lysed by sonication in buffer containing $25 \mathrm{mM}$ HEPES (pH 7.5), $300 \mathrm{mM} \mathrm{NaCl}, 10 \mathrm{mM}$ Imidazole, and $0.5 \mathrm{mM}$ TCEP (Tris(2-CarboxyEthyl)Phosphine). After binding on TALON resin (Ozyme), proteins were eluted using $300 \mathrm{mM}$ of Imidazole and dialyzed at $4^{\circ} \mathrm{C}$ in buffer $20 \mathrm{mM}$ HEPES (pH 7.5), $300 \mathrm{mM} \mathrm{NaCl}$, and $1 \mathrm{mM}$ DTT with PreScission protease to remove the 6xHis-tag.

For crystallization assays, $\mathrm{Bcd} 1_{120-303}$ and Rtt106 $6_{65-301}$ proteins were overexpressed separately and then mixed at a ratio of $1.2: 1$. The complex between the two partners was isolated from Bcdlp monomer by gel filtration on HiLoad 16/ 60 Superdex 200 (GE Healthcare) using an AKTA FPLC system (GE Healthcare) in buffer containing $10 \mathrm{mM}$ Tris (pH 7.5) and $150 \mathrm{mM} \mathrm{NaCl}$. The complex was concentrated to $\sim 10 \mathrm{mg} / \mathrm{mL}$ using a $10 \mathrm{kDa}$ Amicon ${ }^{\circledR}$ device (Millipore).

Preparation of Bcdlp ${ }_{120-303}$ for analysis by NMR included a step of gel filtration using a HiLoad 16/60 Superdex 75 (GE Healthcare) in a buffer containing $10 \mathrm{mM}$ phosphate (pH 6.4), $150 \mathrm{mM} \mathrm{NaCl}$ and $0.5 \mathrm{mM}$ TCEP. The protein was concentrated to $\sim 1 \mathrm{mM}$ using Amicon ${ }^{\circledast}$ device (Millipore). Finally, $10 \% \mathrm{D}_{2} \mathrm{O}(\mathrm{v} / \mathrm{v})$ was added to the sample before the NMR experiments.

1D-SDS-PAGE followed by nanoLC-MS/MS. Gel bands of interest were excised and processed as follows for protein content identification.

Protein preparation for liquid digestion. The gel pieces were successively washed with $50 \mu \mathrm{L}$ of $25 \mathrm{mM} \mathrm{NH}_{4} \mathrm{HCO}_{3}$ and $50 \mu \mathrm{L}$ of acetonitrile (three times), dehydrated with $100 \mu \mathrm{L}$ of acetonitrile before reduction in the presence of $10 \mathrm{mM}$ DTT in $25 \mathrm{mM} \mathrm{NH} \mathrm{HCO}_{3}\left(1 \mathrm{~h}\right.$ at $\left.57^{\circ} \mathrm{C}\right)$, and alkylated in the presence of $55 \mathrm{mM}$ iodoacetamide in $25 \mathrm{mM} \mathrm{NH}_{4} \mathrm{HCO}_{3}$. For tryptic digestion, the gel pieces were resuspended in 2 volumes of trypsin ( $12.5 \mathrm{ng} / \mu \mathrm{L}$; Promega V5111) freshly diluted in $25 \mathrm{mM} \mathrm{NH}_{4} \mathrm{HCO}_{3}$ and incubated overnight at $37^{\circ} \mathrm{C}$. The digested peptides were then extracted from the gel in a buffer containing $34.9 \% \mathrm{H}_{2} \mathrm{O}, 65 \%$ acetonitrile, and $0.1 \% \mathrm{HCOOH}$. The acetonitrile was removed by evaporation and peptides analyzed by nano LC-MS/MS.

Chromatography conditions on NanoAcquity. The analysis was performed on a nanoACQUITY Ultra-Performance-LC (UPLC, Waters Corporation, Milford, USA). The samples were trapped on a $20 \times 0.18 \mathrm{~mm}, 5 \mu \mathrm{m}$ Symmetry C18 precolumn (Waters Corporation, Milford, USA), and the peptides were separated on a ACQUITY UPLC ${ }^{\circ}$ BEH130 C18 column (Waters Corporation, Milford, USA), 75 $\mu \mathrm{m} \times 250 \mathrm{~mm}, 1.7 \mu \mathrm{m}$ particle size. The solvent system consisted of $0.1 \%$ formic acid in water (solvent $\mathrm{A}$ ) and $0.1 \%$ formic acid in acetonitrile (solvent $\mathrm{B}$ ). Trapping was performed during $3 \mathrm{~min}$ at $5 \mu \mathrm{L} / \mathrm{min}$ with $97 \%$ of solvent $A$ and $3 \%$ of solvent B. Elution was performed at a flow rate of $300 \mathrm{~nL} / \mathrm{min}$, using 3-40\% gradient (solvent B) over 79 min followed by $80 \%$ (solvent B) over 10 min at $60{ }^{\circ} \mathrm{C}$.

MS and MS/MS conditions on TripleTOF 5600 mass spectrometer. The MS and MS/MS analyzes were performed on the TripleTOF 5600 an hybrid quadrupole orthogonal acceleration time-of-flight tandem mass spectrometer (ABSciex). The mass spectrometer was operated in positive mode, with the following settings: ion spray voltage floating (ISVF) $2300 \mathrm{~V}$, curtain gas (CUR) $25 \mathrm{psi}$, interface heater temperature (IHT) $75^{\circ} \mathrm{C}$, ion source gas 1 (GS1) $2 \mathrm{psi}$, declustering potential (DP) $100 \mathrm{~V}$. Information-dependent acquisition (IDA) mode was used with top 5 MS/ MS scans. The MS scan had an accumulation time of $250 \mathrm{~ms}$ on $\mathrm{m} / z$ [400-1250] range and the MS/MS scans $100 \mathrm{~ms} \mathrm{~m} / z$ [150-1600] range in high sensitivity mode. Switching criteria were set to ions with charge state of $2-4$ and an abundance threshold of more than 150 counts, exclusion time was set at $12 \mathrm{~s}$. IDA rolling collision energy script was used for automatically adapting the CE. Mass calibration of the analyser was achieved using peptides from digested BSA. The complete system was fully controlled by AnalystTF 1.6 (AB Sciex).

MS/MS data interpretation. The peak list has been searched against a SwissProt database (created 2020-12-15, containing Escherichia coli target sequences and the sequences of the recombinant proteins, using Mascot (version 2.6.2, Matrix science, London, England). The database, which contained sequences of human proteins including common contaminants (human keratins) and porcine trypsin, was created using an in-house database generation toolbox ${ }^{60}$. During database search, up to one missed cleavage by trypsin, one fixed modification carbamidomethylation of Cysteine $(+57 \mathrm{Da})$ and one variable modification oxidation of Methionine $(+16$ $\mathrm{Da}$ ), were considered. The peptide mass tolerance (tolerance of mass measurement for precursor ion) was set to $15 \mathrm{ppm}$ and the MS/MS mass tolerance (tolerance of mass measurement for fragment ion) set to $0.05 \mathrm{Da}$. Proline pipeline was used to validate the identification results. The protein identification validation parameters were set as follows: a peptide with a minimal length of seven amino acid, and an ion score $\geq 25$.

NMR experiments and calculation of $\mathbf{B c d 1}_{120-303}$ structure. The almost complete resonance assignment of ${ }^{13} \mathrm{C} /{ }^{15} \mathrm{~N}$-labeled $\mathrm{Bcd} 1 \mathrm{p}_{120-303}$ was achieved using a standard approach based on 3D NMR spectra recorded at $303 \mathrm{~K}$ using 600 $\mathrm{MHz}$ and $950 \mathrm{MHz}$ (TGIR, Gif-sur-Yvette) Bruker Avance III spectrometers, both equipped with cryoprobes. Initial NMR structures were calculated using the automated procedure of CYANA $3.97^{61}$ using dihedral angle restraints derived from TALOS- $\mathrm{N}^{62}$ and distance restraints derived from $3 \mathrm{D}{ }^{1} \mathrm{H}-{ }^{13} \mathrm{C}$ and ${ }^{1} \mathrm{H}-{ }^{15} \mathrm{~N}-$ NOESY-HSQC spectra. The nOe assignments were carefully checked after the final iteration. Using the AMPS-NMR web portal ${ }^{63}$ [http://pyenmr.cerm.unifi.it/access/ index/amps-nmr], 100 CYANA structures were refined in water against ${ }^{1} \mathrm{H}-{ }^{15} \mathrm{~N}$ RDC restraints measured with the help of Best-TROSY and semi Best-TROSY experiments recorded at $303 \mathrm{~K}$ and $600 \mathrm{MHz}$ in pf1-containing NMR buffer. The 20 structures with the lowest energies were selected as the most representative. In these structures, $99.3 \%$ of residues were favored to generously allowed regions of Ramachandran space and $0.7 \%$ were outside. Dynamics of the backbone were evaluated through measurement of the ${ }^{1} \mathrm{H}-{ }^{15} \mathrm{~N}$ heteronuclear nOe ratios recorded in the same conditions as the ones used for assignment. Figures were prepared with PyMOL 2.2.0.

Isothermal Titration Calorimetry. Interaction experiments between various fragment of Bcdlp and Rtt106p were recorded at $293 \mathrm{~K}$ in buffer containing $10 \mathrm{mM}$ $\mathrm{NaPi}(\mathrm{pH} 7.5), 150 \mathrm{mM} \mathrm{NaCl}$ and $0.5 \mathrm{mM}$ TCEP using an iTC200 microcalorimeter (GE Healthcare). Calorimetric data were analyzed with Origin7 software. Proteins were used at concentrations of $40 \mu \mathrm{M}$ for the titrated and $400 \mu \mathrm{M}$ for the titrant. Interaction experiments between Rtt106 $\mathrm{p}_{65-301}$ (with or without $\mathrm{Bcd} 1 \mathrm{p}_{120-303}$ ) and $\mathrm{H} 3 \mathrm{~K} 56 \mathrm{ac}$ (IRRFQKacSTELL) peptide (Proteogenix) were performed at $200 \mu \mathrm{M}$ for the protein(s) and $2 \mathrm{mM}$ for the peptide as the titrant.

Crystallization and collection of X-ray data. Crystals from the complex formed between Rtt106 $\mathrm{p}_{65-301}$ and $\mathrm{Bcd} 1 \mathrm{p}_{120-303}$ were grown by vapor diffusion in hanging drops. The drops were made at $293 \mathrm{~K}$ by mixing $2 \mu \mathrm{L}$ of the protein solution at $10 \mathrm{mg} / \mathrm{mL}$ and $4 \mu \mathrm{L}$ of a reservoir solution containing 10\% (w/v) PEG $8 \mathrm{~K}, 20 \%(\mathrm{v} / \mathrm{v})$ ethylene glycol, $10 \mathrm{mM}$ 1,6-hexanediol, $10 \mathrm{mM}$ 2-propanol, and $100 \mathrm{mM}$ sodium HEPES at $\mathrm{pH}$ 7.5. These crystals belonged to space group $P 2_{1}$ with unit-cell parameters $a=56.7 \AA, b=66.7 \AA, c=65.1 \AA$, and $\beta=104.7^{\circ}$ (Table 2). Assuming one heterodimer in the asymmetric unit, the packing density $V_{M}$ was $2.46 \AA^{3}$. Da ${ }^{-1}$ and the solvent content was $50.1 \%$. Crystals were flash frozen in liquid nitrogen in the mother liquor with addition of $25 \%$ glycerol as cryoprotectant. A native dataset at $2.79 \AA$ resolution was collected at $100 \mathrm{~K}$ on beamline ID29 at the European Synchrotron Radiation Facility (ESRF, Grenoble), with incident radiation at a wavelength of $1.033 \AA$ and a crystal-to-detector distance of $405 \mathrm{~mm}$. Diffraction spots were recorded on a Pilatus $6 \mathrm{M}-\mathrm{F}$ detector with $0.1^{\circ}$ oscillation and $0.04 \mathrm{~s}$ exposure per image. Data were indexed and scaled using $\mathrm{XDS}^{64}$ and indexed intensities were converted to structure factors using TRUNCATE in the CCP4 suite ${ }^{65}$ without any $\sigma$ cutoff.

Crystal structure determination. The crystal structure of the Rtt106 $\mathrm{p}_{65-301}$ : Bcdl1 ${ }_{120-303}$ complex was solved by molecular replacement with the program PHASER $^{66}$ using the crystal structure of Rtt106p 22 (entry PDB code 3TW1 [https://www.rcsb.org/structure/3TW1]) and the NMR structure of Bcdlp $\mathrm{p}_{120-303}$ (entry PDB code 6NZ2 [https://www.rcsb.org/structure/6NZ2]). A single solution was obtained with $L L G=508$ and TFZ $=26.0$. The model was built using 
$\mathrm{COOT}^{67}$, and the crystal structure was refined in the range $20-2.79 \AA$ using REFMAC $5^{68}$. Ten percent of the native data were selected for $R_{\text {free }}$ calculations. The model was refined to the final $R_{\text {factor }}$ of $21.0 \%$ and $R_{\text {free }}$ of $29.7 \%$ (Table 2) and includes residues 66-118, 121-205, and 218-298 of Rtt106p, residues 128-172, 178-210, 225-247, and 253-301 of Bcdlp. Coordinates of the Rtt106 $\mathrm{p}_{65-301}$ : Bcdl1 $\mathrm{p}_{120-303}$ structure have been deposited in the Protein Data Bank (entry PDB code 6THL [https://www.rcsb.org/structure/6THL]). Over $92 \%$ of the residues were within the most favored regions in a Ramachandran plot, as defined by PROCHECK ${ }^{69}$. Figures were prepared using PyMOL 2.2.0 software.

Nondenaturing Mass Spectrometry (MS). For native MS experiments, individual partners and co-purified Bcdl1 $\mathrm{p}_{\mathrm{FL}}:$ Rtt106 $\mathrm{p}_{65-320}$ complex were buffer exchanged against $150 \mathrm{mM}$ ammonium acetate buffer, $\mathrm{pH} 7.5$ using Zeba microcentrifuge gel filtration columns ( 2 cycles). Protein concentrations were determined by UV absorbance using a NanoDrop 2000 spectrophotometer (Thermo Fisher Scientific, France). Mass spectrometry experiments were carried out on a hybrid electrospray quadrupole time-of-flight mass spectrometer (Synapt G2 HDMS, Waters, Manchester, UK) equipped with an automated chip-based nanoelectrospray source (Triversa Nanomate, Advion Biosciences, Ithaca, USA) operating in the positive ion mode. Denatured MS analysis was performed on the Synapt G2 HDMS instrument with external calibration using the multiply charged ions produced by $2 \mu \mathrm{M}$ horse heart myoglobin solution diluted in water/acetonitrile/formic acid $(50 \mathrm{v} / 50 \mathrm{v} / 1 \mathrm{v})$ and standard interface tuning parameters of the mass spectrometer (Vc, $40 \mathrm{~V} ; \mathrm{Pi}, 2.1 \mathrm{mbar}$ ). For native MS experiments, external calibration was performed using singly charged ions produced by a $2 \mathrm{mg} / \mathrm{mL}$ solution of cesium iodide in 2-propanol/water $(1 \mathrm{v} / 1 \mathrm{v})$. Instrumental parameters were carefully optimized to improve desolvation and ion transfer as well as to maintain noncovalent interactions. In particular, the pressure during the first pumping stage was increased to $6 \mathrm{mBar}$ using a throttling valve and the sample cone voltage Vc was set to 120 and $200 \mathrm{~V}$. Native MS data were interpreted using MassLynx 4.1 (Waters, Manchester, UK).

Ion mobility-Mass spectrometry. Samples were prepared for IM-MS experiments as described above for nondenaturing MS experiments, and the analyses were conducted on the same above-mentioned mass spectrometer. IM parameters were carefully optimized in order to maintain noncovalent complex with the best desolvation possible without ion activation before entering the ion mobility cell. Instrument parameters were: capillary voltage, $1.7 \mathrm{kV}$; cone voltage, $100 \mathrm{~V}$; trap bias, $44.5 \mathrm{~V}$; trap CE, $4 \mathrm{~V}$; transfer CE, $2 \mathrm{~V}$; wave velocity $1053 \mathrm{~m} / \mathrm{s}$; wave height, $40 \mathrm{~V}$; backing pressure, $6 \mathrm{mbar}$; He flow rate, $105 \mathrm{~mL} / \mathrm{min}$; N2 flow rate, $25 \mathrm{~mL} / \mathrm{min}$. The ion ${ }^{{ }^{T W}} \mathrm{CCS}_{\mathrm{N} 2}$ was determined from external calibration with native ions of known ${ }^{\mathrm{DT}} \mathrm{CCS}_{\mathrm{He}}$, i.e., $\beta$-lactoglobulin, transthyretin and bovine serum albumin ${ }^{42}$. IM-MS were acquired in triplicate using identical IM parameters, and the data were processed using MassLynx 4.1 (Waters, Manchester, UK). The crystallographic structure of Rtt106 ${ }_{65-320}$ (entry PDB code 3GYP [https://www.rcsb. org/structure/3GYP]), was visualized using PyMOL 2.2.0 software. Theoretical CCS was calculated using $\mathrm{Mobcal}^{70}$ from the crystal structure.

\section{Partial proteolysis followed by nondenaturing mass spectrometry analysis.} Proteolysis of the Bcdl1 $\mathrm{p}_{\mathrm{FL}} / \mathrm{His}_{6} \mathrm{Rtt} 106 \mathrm{p}-\mathrm{M}$ complex was carried out by mixing 0.7 $\mathrm{U}$ of sequencing grade modified porcine trypsin (Promega, Madison, USA) with $160 \mu \mathrm{g}$ of complex incubated for $4 \mathrm{~h}$ at $20^{\circ} \mathrm{C}$. The sample was then buffer exchanged in $200 \mathrm{mM}$ ammonium acetate $\left(\mathrm{NH}_{4} \mathrm{Ac}\right), \mathrm{pH} 8$ buffer using Zeba spin desalting columns (Thermo Fisher Scientific, Waltham, MA USA). The concentration of the complex was determined by UV absorbance on a Nanodrop 2000 spectrophotometer (Thermo Fisher Scientific USA). Nanoelectrospray mass spectrometry analysis was performed on an LC-time-of-flight mass spectrometer (Micromass) coupled with an automated chip-based nanoESI source (Triversa Nanomate, Advion Biosciences, Ithaca, NY). The sample was infused at $5 \mu \mathrm{M}$ by dilution in $200 \mathrm{mM} \mathrm{NH}_{4} \mathrm{Ac}$, pH 8 buffer. Instrumental parameters for analysis were optimized by raising the backing pressure to $7 \mathrm{mbar}$ and the cone voltage to 200 V. Data were treated using MassLynx 4.1 software (Waters, Manchester, UK).

HDX-MS. Samples were prepared and injected with an automated HDX system including a CTC PAL robot (Leap Technologies, Zwingen, Switzerland), coupled to a nanoAcquity UPLC system with HDX technology (Waters, Manchester, UK). Individual proteins and complex were prepared in a $10 \mathrm{mM}$ potassium phosphate, $150 \mathrm{mM} \mathrm{NaCl}, \mathrm{pH} 7.5$ buffer. After dilution, the samples were incubated at $20^{\circ} \mathrm{C}$ for different deuteration times $(0.5,2,10,30$, and $60 \mathrm{~min})$ in $10 \mathrm{mM}$ potassium phosphate, $150 \mathrm{mM} \mathrm{NaCl}$, pD7.5 deuterated buffer. The exchange reaction was stopped by adding $1: 1(\mathrm{v} / \mathrm{v})$ of $100 \mathrm{mM}$ potassium phosphate, $100 \mathrm{mM}$ TCEP, $2 \mathrm{M}$ $\mathrm{GdHCl}, \mathrm{pH} 2.3$ quench buffer at $1{ }^{\circ} \mathrm{C}$ for $0.5 \mathrm{~min}$. Quenched samples were then digested (100 pmoles injections) through a pepsin-immobilized cartridge (Enzymate pepsin column, $300 \AA, 5 \mu \mathrm{m}, 2.1 \times 30 \mathrm{~mm}$, Waters, Manchester, UK) in $0.1 \%$ aqueous formic acid solution and generated peptides were trapped on UPLC precolumn (ACQUITY UPLC BEH C18 VanGuard precolumn, $2.1 \mathrm{~mm}$ I.D. $\times$ $5 \mathrm{~mm}, 1.7 \mu \mathrm{M}$ particle diameter, Waters, Manchester, UK) at $200 \mu \mathrm{l} \cdot \mathrm{min}^{-1}$. Digested peptides were then separated on UPLC column (ACQUITY UPLC BEH C18, $1.0 \mathrm{~mm}$ I.D. $\times 100 \mathrm{~mm}, 1.7 \mu \mathrm{M}$ particle diameter, Waters, Manchester, UK) at
$0.1{ }^{\circ} \mathrm{C}$ with a gradient elution of solvent $\mathrm{A}(0.1 \%$ formic acid aqueous $)$ and solvent B (acetonitrile with $0.1 \%$ formic acid) $[2-40 \%$ B $(7 \mathrm{~min}), 40-85 \%$ B ( $0.5 \mathrm{~min})$, and $85 \% \mathrm{~B}(1 \mathrm{~min})]$ at a flow rate of $40 \mu \mathrm{L} \cdot \mathrm{min}^{-1}$. Mass spectrometry analyses were conducted on a Synapt G2 HDMS (Waters, Manchester, UK) with an electrospray ionization in positive polarity, initially calibrated and using a lock-mass correction with glufibrinogen peptide. Analyses were carried out in data-independent acquisition mode (MSE, Waters, Manchester, UK) with the following parameters: ESI voltage, $3.2 \mathrm{kV}$; cone voltage, $40 \mathrm{~V}$; source temperature, $80^{\circ} \mathrm{C}$; desolvation gas nitrogen at $150^{\circ} \mathrm{C}$ and $800 \mathrm{~L} \cdot \mathrm{h}^{-1}$; acquisition range, $\mathrm{m} / z$ 50-2000; scan time, $0.3 \mathrm{~s}$; trap MS collision, $15 \rightarrow 40 \mathrm{eV}$. MS ${ }^{\mathrm{E}}$ data were processed using ProteinLynx Global Server 2.5.3 (Waters, Manchester, UK) with a custom protein sequence library, where peptide and fragment tolerances were set automatically by PLGS, with oxidized methionine as variable modification. Data were then processed with DynamX 3.0 (Waters, Manchester, UK) as follows: all experiments were carried out in triplicate and only peptides identified in all replicates were kept with a minimum fragment of 0.2 per amino acid, a minimum intensity of $10^{3}$, a length between 5 and 30 residues and a file threshold of 3 . Deuterium uptakes for all identified peptides were manually checked and validated. Only one charge state was kept for each peptide and deuterium uptakes were not corrected for back-exchange, represented as relative. HDX-MS results were statistically validated using a mixed effects model (MEMHDX ${ }^{71}$ ), with a $P$ value set to 0.01 . HDX data were exported on crystal structure using PyMOL 2.2.0 software.

\section{XL-MS experiments}

$X L$ reaction. The chemical XL agent used was an equimolar mix of light $(\mathrm{d} 0)$ and heavy (d4) BS3. The XL experiment was performed in stock protein buffer $(10 \mathrm{mM}$ HEPES, $150 \mathrm{mM} \mathrm{NaCl}$, pH 7.5). For XL reactions $(20 \mu \mathrm{L}), 70 \mu \mathrm{M}$ of complex was used in two ratios (1:50 and 1:100) of BS3-d0/d4 and one control with no cross-link reagent. The reaction occurred for $1 \mathrm{~h}$ at room temperature and was then quenched by adding $1.05 \mu \mathrm{L}$ of bicarbonate ammonium solution at $400 \mathrm{mM}$. Samples were then deposited and separated on acrylamide 10\% SDS-PAGE. XL reaction were performed in technical duplicates on two independent Bcdl $\mathrm{p}_{\mathrm{FL}} / \mathrm{Rtt106p}-\mathrm{M}$ purification batches.

In-gel digestion. Bands corresponding to the cross-linked proteins for each XL reagent concentration were cut and subjected to in-gel digestion using an automated protein digestion system, MassPrep Station (Waters, Manchester, UK). The gel plugs were first destained three times with $100 \mu \mathrm{L}$ of $25 \mathrm{mM}$ ammonium hydrogen carbonate $\left(\mathrm{NH}_{4} \mathrm{HCO}_{3}\right)$ /acetonitrile $(\mathrm{ACN})(50 / 50)$. They were then dehydrated with $50 \mu \mathrm{L} \mathrm{ACN}$. The cysteine residues were reduced by adding $50 \mu \mathrm{L}$ dithiothreitol (DTT) at $10 \mathrm{mM}$ for $30 \mathrm{~min}$ at $60^{\circ} \mathrm{C}$ followed by $30 \mathrm{~min}$ at room temperature, and alkylated by adding iodoacetamide (IAA) at $55 \mathrm{mM}$ for $20 \mathrm{~min}$. The bands were then washed by adding $50 \mu \mathrm{L}$ of $\mathrm{NH}_{4} \mathrm{HCO}_{3} 25 \mathrm{mM}$ and $50 \mu \mathrm{L}$ ACN. After dehydration with ACN, the gel bands were stored at $-20^{\circ} \mathrm{C}$ until digestion. The proteins were cleaved by adding $25 \mu \mathrm{L}$ of a modified porcine trypsin solution at $4 \mathrm{ng} / \mu \mathrm{L}$ in $25 \mathrm{mM} \mathrm{NH}_{4} \mathrm{HCO}_{3}$. Digestion was performed overnight at 37 ${ }^{\circ} \mathrm{C}$. Tryptic peptides were extracted twice: the first time with $40 \mu \mathrm{L}$ of $60 \% \mathrm{ACN}$ in $0.1 \%$ Formic Acid (FA) for $1 \mathrm{~h}$ and the second time with $40 \mu \mathrm{L}$ of $100 \%$ ACN for $1 \mathrm{~h}$.

The collected extracts were pooled and excess ACN was evaporated under vacuum with a SpeedVac ${ }^{\text {mx }}$ (Thermo Scientific, Waltham, USA). All the extracted peptides were pooled in one well per XL reagent concentration and again evaporated under vacuum to a final volume of $57 \mu \mathrm{L}$.

$X L-M S$ analysis. Nanocapillary liquid chromatography-tandem mass spectrometry (nanoLC-MS/MS) was performed with a nanoLC-Orbitrap-MS system. The system was controlled by X-Calibur ${ }^{\mathrm{mm}}$ (v.3.0.63, Thermo Scientific, Waltham, USA). The nanoLC system was composed of ACQUITY UPLC ${ }^{\circledR}$ BEH130 C18 column (250 $\mathrm{mm} \times 75 \mu \mathrm{m}$ with $1.7 \mu \mathrm{m}$ particle size, Waters Corporation, Milford, USA) and a Symmetry C18 precolumn $(20 \mathrm{~mm} \times 180 \mu \mathrm{m}$ with $5 \mu \mathrm{m}$ particle size, Waters Corporation, Milford, USA). The solvent system consisted of $0.1 \% \mathrm{FA}$ in water (solvent A) and $0.1 \%$ FA in ACN (solvent B). Samples $(2 \mu \mathrm{L})$ were loaded into the enrichment column for $5 \mathrm{~min}$ at $5 \mu \mathrm{L} / \mathrm{min}$ with $99 \%$ of solvent $\mathrm{A}$ and $1 \%$ of solvent B. Peptides were eluted at a flow rate of $450 \mathrm{~nL} / \mathrm{min}$ with a $1-35 \%$ linear gradient of solvent B in $79 \mathrm{~min}$. Analyses were performed on a Q-Exactive + (Thermo Scientific, Waltham, USA) with the capillary voltage set to $1.6 \mathrm{kV}$ at $250{ }^{\circ} \mathrm{C}$. The system was operated in data-dependent-acquisition (DDA) mode with automatic switching between MS (50 ms/scan on $\mathrm{m} / \mathrm{z}$ range [300-1800] with $\mathrm{R}=70,000)$ and MS/MS (100 ms/scan on $\mathrm{m} / \mathrm{z}$ range [200-2200] with $\mathrm{R}=17,500)$ modes. Samples digested in-gel were analyzed using the following MSMS method: the 10 most abundant peptides (intensity threshold $1.5 .10^{5}$ ), excluding mono and doubled charged ions, were selected on each MS spectrum for further isolation and HCD fragmentation (dynamic exclusion $30 \mathrm{sec}$ ). Mass data collected during analysis were processed and converted into.mgf files using MSConvert. The MS/MS data were interpreted using StavroX software v.3.6.6 $6^{72}$. Spectra were searched with a mass tolerance of $5 \mathrm{ppm}$ for MS, $10 \mathrm{ppm}$ for MS/MS and using trypsin as enzyme. Lys and Arg were considered as protease cleavage sites with a maximum of three missed cleavages. Carbamidomethylation of cysteine was set as fixed and oxidation of methionine as variable modifications (max. mod. 2). Primary amino groups (Lys side chains and N-termini) as well as primary hydroxyl groups (Ser, Thr, and Tyr 
side chains) were considered as cross-linking sites. Cross-links composed of consecutive amino-acid sequences were not considered. Heavy and light BS3 crosslinked peptides were validated using an FDR cutoff of $5 \%$. Each conjugation site was manually validated based on the presence of $y$-ion and b-ion and peak intensity observed on the MS/MS spectra. After validation at the MS/MS level, QualBrowser (Thermo Xcalibur 3.0.63) was used to validate the equimolar ratio between the heavy and light cross-linked peptides at the MS level. Only peptides present in the two technical replicates of each individual cross-linker ratio were considered as validated. The list of validated cross-links for the complex Bcdlp $\mathrm{p}_{\mathrm{FL}}$ : Rtt106p-M is in Supplementary Table 2. Finally, PyMOL 2.2.0 software. was used to calculate the $\mathrm{Ca}-\mathrm{Ca}$ distance of each validated linkage sites.

Reporting summary. Further information on research design is available in the Nature Research Reporting Summary linked to this article.

\section{Data availability}

Genetic interaction mapping data that support the findings of this study have been deposited in NCBI GEO with the accession code GSE118550. The gene ontology resource [http://geneontology.org/] was used for information on protein sequences. Bcd1 protein sequences used during the current study are available from UniProt with the entry identifiers in Saccharomyces cerevisiae ([https://www.uniprot.org/uniprot/P38772], Homo sapiens [https:// www.uniprot.org/uniprot/Q9NWK9], Mus musculus [https:// www.uniprot.org/uniprot/Q3UFB2], Schizosaccharomyces pombe [https://www.uniprot org/uniprot/O74906], and from GenBank with the accession numbers in Talaromyces islandicus [https://www.ncbi.nlm.nih.gov/protein/816194281], Candida glabrata [https:// www.ncbi.nlm.nih.gov/protein/961789889], Candida albicans [https://www.ncbi.nlm.nih. gov/protein/723165737], Pichia kudriavzevii [https:/www.ncbi.nlm.nih.gov/protein/ 1402408442], Yarrowia lipolytica [https://www.ncbi.nlm.nih.gov/protein/1078658162]. 3D data that support the findings of this study have been deposited in the Biological Magnetic Resonance Data Bank (access code 30570) and Protein Data Bank (entry code $6 \mathrm{NZ2}$ [https://doi.org/10.2210/pdb6NZ2/pdb]) for NMR data. X-ray data have been deposited in the Protein Data Bank (entry code 6THL [https://doi.org/10.2210/ $\mathrm{pdb} 6 \mathrm{THL} / \mathrm{pdb}$ ). The mass spectrometry and proteomic data that support the findings of this study have been deposited to the ProteomeXchange Consortium via the PRIDE [https://www.ebi.ac.uk/pride/archive/] partner repository with the dataset identifier PXD023434. This submission includes all HDX-MS raw data files, Cluster and State data files (csv output files from DynamX), H/D plots ppt file, XL-MS raw data files, an Excel file summarizing MS information from all validated XL peptides, a FASTA file of the sequences used in structural MS experiments, Gel bands analyses raw data files, FASTA file used for Mascot research and excel file summarizing MS information of all peptides and proteins identified. Source data are provided with this paper.

Received: 17 December 2019; Accepted: 26 February 2021; Published online: 25 March 2021

\section{References}

1. Watkins, N. J. \& Bohnsack, M. T. The box C/D and H/ACA snoRNPs: key players in the modification, processing and the dynamic folding of ribosomal RNA. Wiley Interdiscip. Rev. RNA 3, 397-414 (2012).

2. Lafontaine, D. L. Noncoding RNAs in eukaryotic ribosome biogenesis and function. Nat. Struct. Mol. Biol. 22, 11-19 (2015).

3. Bachellerie, J. P., Cavaille, J. \& Huttenhofer, A. The expanding snoRNA world. Biochimie 84, 775-790 (2002).

4. Henras, A. K., Plisson-Chastang, C., O'Donohue, M. F., Chakraborty, A. \& Gleizes, P. E. An overview of pre-ribosomal RNA processing in eukaryotes. Wiley Interdiscip. Rev. RNA 6, 225-242 (2015).

5. Turowski, T. W. \& Tollervey, D. Cotranscriptional events in eukaryotic ribosome synthesis. Wiley Interdiscip. Rev. RNA 6, 129-139 (2015).

6. Massenet, S., Bertrand, E. \& Verheggen, C. Assembly and trafficking of box C/D and H/ACA snoRNPs. RNA Biol. 14, 680-692 (2017).

7. Rothe, B. et al. Protein Hitl, a novel box C/D snoRNP assembly factor, controls cellular concentration of the scaffolding protein Rsal by direct interaction. Nucleic Acids Res. 42, 10731-10747 (2014).

8. Boulon, S. et al. The Hsp90 chaperone controls the biogenesis of L7Ae RNPs through conserved machinery. J. Cell Biol. 180, 579-595 (2008).

9. Zhao, R. et al. Molecular chaperone Hsp90 stabilizes Pih1/Nop17 to maintain R2TP complex activity that regulates snoRNA accumulation. J. Cell Biol. 180, 563-578 (2008).

10. Hiley, S. L., Babak, T. \& Hughes, T. R. Global analysis of yeast RNA processing identifies new targets of RNase III and uncovers a link between tRNA 5' end processing and tRNA splicing. Nucleic Acids Res. 33, 3048-3056 (2005).

11. Peng, W. T. et al. A panoramic view of yeast noncoding RNA processing. Cell 113, 919-933 (2003).
12. Paul, A. et al. Bcdlp controls RNA loading of the core protein Nop58 during C/D box snoRNP biogenesis. RNA https://doi.org/10.1261/rna.067967.118 (2019).

13. Khoshnevis, S., Dreggors, R. E., Hoffmann, T. F. R. \& Ghalei, H. A conserved Bcd1 interaction essential for box C/D snoRNP biogenesis. J. Biol. Chem. https://doi.org/10.1074/jbc.RA119.010222 (2019).

14. Bizarro, J. et al. Proteomic and 3D structure analyses highlight the $\mathrm{C} / \mathrm{D}$ box snoRNP assembly mechanism and its control. J. Cell Biol. 207, 463-480 (2014).

15. McKeegan, K. S., Debieux, C. M., Boulon, S., Bertrand, E. \& Watkins, N. J. A dynamic scaffold of pre-snoRNP factors facilitates human box C/D snoRNP assembly. Mol. Cell. Biol. 27, 6782-6793 (2007).

16. McKeegan, K. S., Debieux, C. M. \& Watkins, N. J. Evidence that the AAA+ proteins TIP48 and TIP49 bridge interactions between $15.5 \mathrm{~K}$ and the related NOP56 and NOP58 proteins during box C/D snoRNP biogenesis. Mol. Cell. Biol. 29, 4971-4981 (2009).

17. Rodor, J. et al. AtNUFIP, an essential protein for plant development, reveals the impact of snoRNA gene organisation on the assembly of snoRNPs and rRNA methylation in Arabidopsis thaliana. Plant J. Cell Mol. Biol. 65, 807-819 (2011).

18. Rodor, J., Letelier, I., Holuigue, L. \& Echeverria, M. Nucleolar RNPs: from genes to functional snoRNAs in plants. Biochem. Soc. Trans. 38, 672-676 (2010).

19. Houry, W. A., Bertrand, E. \& Coulombe, B. The PAQosome, an R2TP-based chaperone for quaternary structure formation. Trends Biochem. Sci. 43, 4-9 (2018).

20. Huang, S. et al. Rtt106p is a histone chaperone involved in heterochromatinmediated silencing. Proc. Natl Acad. Sci. USA 102, 13410-13415 (2005).

21. Yang, J. et al. The histone chaperone FACT contributes to DNA replicationcoupled nucleosome assembly. Cell Rep. 14, 1128-1141 (2016).

22. Su, D. et al. Structural basis for recognition of H3K56-acetylated histone H3H4 by the chaperone Rtt106. Nature 483, 104-107 (2012).

23. Clemente-Ruiz, M., Gonzalez-Prieto, R. \& Prado, F. Histone H3K56 acetylation, CAF1, and Rtt106 coordinate nucleosome assembly and stability of advancing replication forks. PLoS Genet. 7, e1002376 (2011).

24. Fazly, A. et al. Histone chaperone Rtt106 promotes nucleosome formation using (H3-H4)2 tetramers. J. Biol. Chem. 287, 10753-10760 (2012).

25. Li, Q. et al. Acetylation of histone $\mathrm{H} 3$ lysine 56 regulates replication-coupled nucleosome assembly. Cell 134, 244-255 (2008).

26. Zunder, R. M., Antczak, A. J., Berger, J. M. \& Rine, J. Two surfaces on the histone chaperone Rtt106 mediate histone binding, replication, and silencing. Proc. Natl Acad. Sci. USA 109, E144-E153 (2012).

27. Huang, S., Zhou, H., Tarara, J. \& Zhang, Z. A novel role for histone chaperones CAF-1 and Rtt106p in heterochromatin silencing. EMBO J. 26, 2274-2283 (2007)

28. Amin, A. D., Vishnoi, N. \& Prochasson, P. A global requirement for the HIR complex in the assembly of chromatin. Biochim. Biophys. Acta 1819, 264-276 (2013).

29. Imbeault, D., Gamar, L., Rufiange, A., Paquet, E. \& Nourani, A. The Rtt106 histone chaperone is functionally linked to transcription elongation and is involved in the regulation of spurious transcription from cryptic promoters in yeast. J. Biol. Chem. 283, 27350-27354 (2008).

30. Silva, A. C. et al. The replication-independent histone H3-H4 chaperones HIR ASF1, and RTT106 co-operate to maintain promoter fidelity. J. Biol. Chem. 287, 1709-1718 (2012).

31. Giaever, G. et al. Functional profiling of the Saccharomyces cerevisiae genome Nature 418, 387-391 (2002).

32. Decourty, L. et al. Long open reading frame transcripts escape nonsensemediated mRNA decay in yeast. Cell Rep. 6, 593-598 (2014).

33. Schuldiner, M. et al. Exploration of the function and organization of the yeast early secretory pathway through an epistatic miniarray profile. Cell 123, 507-519 (2005).

34. Benschop, J. J. et al. A consensus of core protein complex compositions for Saccharomyces cerevisiae. Mol. cell 38, 916-928 (2010).

35. Luo, W., Friedman, M. S., Shedden, K., Hankenson, K. D. \& Woolf, P. J. GAGE: generally applicable gene set enrichment for pathway analysis. $B M C$ Bioinformatics 10, 161 (2009).

36. Kufel, J., Allmang, C., Verdone, L., Beggs, J. \& Tollervey, D. A complex pathway for 3' processing of the yeast U3 snoRNA. Nucleic Acids Res. 31, 6788-6797 (2003).

37. Morlando, M. et al. Coupling between snoRNP assembly and 3' processing controls box C/D snoRNA biosynthesis in yeast. $Е M B O ~ J . ~ 23,2392-2401$ (2004).

38. Lambert, J. P. et al. Defining the budding yeast chromatin-associated interactome. Mol. Syst. Biol. 6, 448 (2010).

39. Hondele, M. et al. Structural basis of histone $\mathrm{H} 2 \mathrm{~A}-\mathrm{H} 2 \mathrm{~B}$ recognition by the essential chaperone FACT. Nature 499, 111-114 (2013).

40. Kemble, D. J. et al. Structure of the Spt16 middle domain reveals functional features of the histone chaperone FACT. J. Biol. Chem. 288, 10188-10194 (2013). 
41. Bragantini, B. et al. Functional and structural insights of the zinc-finger HIT protein family members Involved in Box C/D snoRNP biogenesis. J. Mol. Biol. 428, 2488-2506 (2016).

42. Bush, M. F. et al. Collision cross sections of proteins and their complexes: a calibration framework and database for gas-phase structural biology. Anal. Chem. 82, 9557-9565 (2010).

43. Ferreira, M. E., Flaherty, K. \& Prochasson, P. The Saccharomyces cerevisiae histone chaperone Rtt106 mediates the cell cycle recruitment of SWI/SNF and RSC to the HIR-dependent histone genes. PLoS ONE 6, e21113 (2011).

44. Fillingham, J. et al. Two-color cell array screen reveals interdependent roles for histone chaperones and a chromatin boundary regulator in histone gene repression. Mol. Cell 35, 340-351 (2009).

45. Avvakumov, N., Nourani, A. \& Cote, J. Histone chaperones: modulators of chromatin marks. Mol. cell 41, 502-514 (2011).

46. Liu, Y. et al. Structural analysis of Rtt106p reveals a DNA binding role required for heterochromatin silencing. J. Biol. Chem. 285, 4251-4262 (2010).

47. Marcsisin, S. R. \& Engen, J. R. Hydrogen exchange mass spectrometry: what is it and what can it tell us? Anal. Bioanal. Chem. 397, 967-972 (2010).

48. Schopf, F. H. et al. The Co-chaperone Cns1 and the recruiter protein Hgh1 Link Hsp90 to translation elongation via chaperoning elongation factor 2. Mol. cell 74, 73-87 e78 (2019).

49. de Los Santos-Velazquez, A. I., de Oya, I. G., Manzano-Lopez, J. \& MonjeCasas, F. Late rDNA condensation ensures timely Cdc14 release and coordination of mitotic exit signaling with nucleolar segregation. Curr. Biol. 27, 3248-3263 e3245 (2017).

50. Fuhrmann, D., Mernberger, M., Nist, A., Stiewe, T. \& Elsasser, H. P. Miz1 controls Schwann cell proliferation via $\mathrm{H} 3 \mathrm{~K} 36(\mathrm{me} 2)$ demethylase $\mathrm{Kdm} 8$ to prevent peripheral nerve demyelination. J. Neurosci. 38, 858-877 (2018).

51. Rothe, B. et al. Characterization of the interaction between protein Snu13p/ $15.5 \mathrm{~K}$ and the Rsalp/NUFIP factor and demonstration of its functional importance for snoRNP assembly. Nucleic Acids Res. 42, 2015-2036 (2014).

52. Burgess, R. J. \& Zhang, Z. Histone chaperones in nucleosome assembly and human disease. Nat. Struct. Mol. Biol. 20, 14-22 (2013).

53. Williams, S. K., Truong, D. \& Tyler, J. K. Acetylation in the globular core of histone $\mathrm{H} 3$ on lysine-56 promotes chromatin disassembly during transcriptional activation. Proc. Natl Acad. Sci. USA 105, 9000-9005 (2008).

54. Collins, S. R. et al. Functional dissection of protein complexes involved in yeast chromosome biology using a genetic interaction map. Nature 446, 806-810 (2007).

55. Costanzo, M. et al. A global genetic interaction network maps a wiring diagram of cellular function. Science https://doi.org/10.1126/science.aaf1420 (2016).

56. Schwabish, M. A. \& Struhl, K. The Swi/Snf complex is important for histone eviction during transcriptional activation and RNA polymerase II elongation in vivo. Mol. Cell. Biol. 27, 6987-6995 (2007).

57. Diebold, M. L., Fribourg, S., Koch, M., Metzger, T. \& Romier, C. Deciphering correct strategies for multiprotein complex assembly by co-expression: application to complexes as large as the histone octamer. J. Struct. Biol. 175, 178-188 (2011).

58. Decourty, L. et al. Linking functionally related genes by sensitive and quantitative characterization of genetic interaction profiles. Proc. Natl Acad. Sci. USA 105, 5821-5826 (2008).

59. Malabat, C. \& Saveanu, C. Identification of links between cellular pathways by genetic interaction mapping (GIM). Methods Mol. Biol. 1361, 325-343 (2016).

60. Carapito, C. et al. MSDA, a proteomics software suite for in-depth Mass Spectrometry Data Analysis using grid computing. Proteomics 14, 1014-1019 (2014).

61. Lopez-Mendez, B. \& Guntert, P. Automated protein structure determination from NMR spectra. J. Am. Chem. Soc. 128, 13112-13122 (2006).

62. Shen, Y. \& Bax, A. Protein backbone and sidechain torsion angles predicted from NMR chemical shifts using artificial neural networks. J. Biomol. NMR 56, 227-241 (2013).

63. Bertini, I., Case, D. A., Ferella, L., Giachetti, A. \& Rosato, A. A Grid-enabled web portal for NMR structure refinement with AMBER. Bioinformatics 27, 2384-2390 (2011).

64. Kabsch, W. Xds. Acta Crystallogr. Sect. D. Biol. Crystallogr. 66, 125-132 (2010).

65. Winn, M. D. et al. Overview of the CCP4 suite and current developments. Acta Crystallogr. Sect. D. Biol. Crystallogr. 67, 235-242 (2011).

66. McCoy, A. J. et al. Phaser crystallographic software. J. Appl. Crystallogr. 40 658-674 (2007).

67. Emsley, P., Lohkamp, B., Scott, W. G. \& Cowtan, K. Features and development of Coot. Acta Crystallogr. Sect. D. Biol. Crystallogr. 66, 486-501 (2010).

68. Vagin, A. A. et al. REFMAC5 dictionary: organization of prior chemical knowledge and guidelines for its use. Acta Crystallogr. Sect. D. Biol. Crystallogr. 60, 2184-2195 (2004).

69. Laskowski, R. A., Moss, D. S. \& Thornton, J. M. Main-chain bond lengths and bond angles in protein structures. J. Mol. Biol. 231, 1049-1067 (1993).
70. Ruotolo, B. T., Benesch, J. L., Sandercock, A. M., Hyung, S. J. \& Robinson, C. V. Ion mobility-mass spectrometry analysis of large protein complexes. Nat. Protoc. 3, 1139-1152 (2008).

71. Hourdel, V. et al. MEMHDX: an interactive tool to expedite the statistical validation and visualization of large HDX-MS datasets. Bioinformatics 32, 3413-3419 (2016).

72. Gotze, M. et al. StavroX-a software for analyzing crosslinked products in protein interaction studies. J. Am. Soc. Mass Spectrom. 23, 76-87 (2012).

\section{Acknowledgements}

This work was supported by the Centre National de la Recherche Scientifique (CNRS), Université de Lorraine (UL), and Université de Strasbourg; the Agence Nationale de la Recherche [ANR-06-BLAN-0208; ANR-11-BSV8-01503; ANR-16-CE11-0032-04; ANR08-JCJC-0019]; the French Proteomic Infrastructure (ProFI; ANR-10-INBS-08-03). The authors thank GIS IBiSA, Région Alsace, Communauté Urbaine de Strasbourg, FEDER, and the IdeX program of the University of Strasbourg for financial support in purchasing HDX-MS and native MS instruments. B.B., B.R., and A.P. are fellows of the French Ministère de l'Enseignement Supérieur et de la Recherche. M.B. was supported by a fellowship from the Région Alsace. G.T. was supported by the Région Alsace and Novalix. We acknowledge the proteomics and structural biology (ITC, X-rays and NMR) core facilities of UMS2008/US40 IBSLor. We thank IR-RMN FR3050 CNRS for access to the $950 \mathrm{MHz}$ NMR spectrometer in Gif/Yvette (France). We are grateful to ESRF for access to the ID29 beamline. Alain Jacquier, Emmanuel Frachon, Antonia Doyen and Christophe Malabat are acknowledged for their participation in the high-throughput GIM project. Georges Mer is warmly thanked for providing us with the Rtt106p:(H3: $\mathrm{H} 4)_{2}$ model.

\section{Author contributions}

B.B., C.C., M.B., A.P., D.T., B.R., H.M., G.T., S.H., L.D., M.-E.C., J.-M.S., M.Q., C.S., S.L. and X.M. performed the experiments. D.T. and B.R. started the initial experiments on Bcdlp and the study by $\mathrm{Y} 2 \mathrm{H}$ of its interaction with Rtt106p. L.D. and C.S. performed GIM screens. M.B., G.T., and S.H. collected mass spectrometry data, J.-M.S. identified proteins from 1D gel bands, and S.C. helped analyze and interpret the results. B.B. and M.Q. solved the NMR 3D structure. B.B. performed ITC experiments. B.B. and M.-E.C purified the proteins. B.B. and C.C. performed crystallization and collected X-rays data. C.C. interpreted X-rays data. A.P., H.M., and S.L. performed co-IP, RIP, and ChIP. E.B., C.S., S.C., S.L., X.M., and B.C. conceived the study. S.M., E.B., C.S., S.C., S.L., X.M., and B.C. supervised the work. C.C., M.Q., C.S., S.C., S.L., X.M., and B.C. wrote the manuscript.

\section{Competing interests}

The authors declare no competing interests.

\section{Additional information}

Supplementary information The online version contains supplementary material available at https://doi.org/10.1038/s41467-021-22077-4.

Correspondence and requests for materials should be addressed to S.L., X.M. or B.C.

Peer review information Nature Communications thanks Konstantinos Tzelepis and the other, anonymous, reviewers for their contributions to the peer review of this work.

Reprints and permission information is available at http://www.nature.com/reprints

Publisher's note Springer Nature remains neutral with regard to jurisdictional claims in published maps and institutional affiliations.

\section{(i)}

Open Access This article is licensed under a Creative Commons Attribution 4.0 International License, which permits use, sharing, adaptation, distribution and reproduction in any medium or format, as long as you give appropriate credit to the original author(s) and the source, provide a link to the Creative Commons license, and indicate if changes were made. The images or other third party material in this article are included in the article's Creative Commons license, unless indicated otherwise in a credit line to the material. If material is not included in the article's Creative Commons license and your intended use is not permitted by statutory regulation or exceeds the permitted use, you will need to obtain permission directly from the copyright holder. To view a copy of this license, visit http://creativecommons.org/ licenses/by/4.0/.

(C) The Author(s) 2021 